Climate Dynamics

April 2016, Volume 46 Issue 7-8 Pages 2633-2655

http://dx.doi.org/10.1007/s00382-015-2721-z

http://archimer.ifremer.fr/doc/00332/44335/

(C) Springer-Verlag Berlin Heidelberg 2015

\title{
Intraseasonal variability of mixed layer depth in the tropical Indian Ocean
}

\author{
Keerthi M. G. ${ }^{1,}$, Lengaigne M. ${ }^{2,3}$, Drushka K. ${ }^{4}$, Vialard J. ${ }^{2}$, De Boyer Montegut Clement ${ }^{5}$, \\ Pous Stephane ${ }^{2,6}$, Levy M. ${ }^{2}$, Muraleedharan P. M. ${ }^{1}$
}

${ }^{1}$ CSIR, Natl Inst Oceanog, Panaji 403004, Goa, India.

${ }^{2}$ Univ Paris 06, Univ Paris 04, LOCEAN, CNRS IRD MNHN,IPSL, Paris, France.

${ }^{3}$ NIO, Joint Int Lab, Indofrench Cell Water Sci, IISc NIO IITM IRD, Panaji, Goa, India.

${ }_{5}^{4}$ Univ Washington, Appl Phys Lab, Seattle, WA 98105 USA.

${ }^{5}$ IFREMER, Lab Oceanog Spatiale, Brest, France.

${ }^{6}$ Univ Cape Town, Dept Oceanog, Cape Town, South Africa.

*Corresponding author : M. G. Keerthi, email address : keerthanaamg@gmail.com

\begin{abstract}
:
In this paper, we use an observational dataset built from Argo in situ profiles to describe the main largescale patterns of intraseasonal mixed layer depth (MLD) variations in the Indian Ocean. An eddy permitting ( $0.25 \mathrm{~A}$ degrees) regional ocean model that generally agrees well with those observed estimates is then used to investigate the mechanisms that drive MLD intraseasonal variations and to assess their potential impact on the related SST response. During summer, intraseasonal MLD variations in the Bay of Bengal and eastern equatorial Indian Ocean primarily respond to active/break convective phases of the summer monsoon. In the southern Arabian Sea, summer MLD variations are largely driven by seemingly-independent intraseasonal fluctuations of the Findlater jet intensity. During winter, the Madden-Julian Oscillation drives most of the intraseasonal MLD variability in the eastern equatorial Indian Ocean. Large winter MLD signals in northern Arabian Sea can, on the other hand, be related to advection of continental temperature anomalies from the northern end of the basin. In all the aforementioned regions, peak-to-peak MLD variations usually reach $10 \mathrm{~m}$, but can exceed $20 \mathrm{~m}$ for the largest events. Buoyancy flux and wind stirring contribute to intraseasonal MLD fluctuations in roughly equal proportions, except for the Northern Arabian Sea in winter, where buoyancy fluxes dominate. A simple slab ocean analysis finally suggests that the impact of these MLD fluctuations on intraseasonal sea surface temperature variability is probably rather weak, because of the compensating effects of thermal capacity and sunlight penetration: a thin mixed-layer is more efficiently warmed at the surface by heat fluxes but loses more solar flux through its lower base.
\end{abstract}




\section{Introduction}

The mixed-layer, i.e., the quasi-homogeneous upper ocean layer with a fairly uniform density profile, is critical to the ocean variability as it acts as the interface between the atmosphere and ocean interior. This layer is also an essential parameter for air-sea interactions: a shallow Mixed Layer Depth (MLD) exhibits a reduced thermal capacity and can hence promote large sea surface temperature (SST) anomalies (e.g. Shinoda and Hendon, 1998). This is particularly critical in the Indian Ocean (IO), $40 \%$ of which is covered by waters warmer than $28.5^{\circ} \mathrm{C}$. At those high surface temperatures, small SST perturbations can induce strong variations of the deep atmospheric convection (Gadgil et al. 1984) with both local and remote consequences on the atmospheric circulation (see review by Schott et al. 2009). In addition to air-sea interaction, MLD also affects the primary productivity and the timing of phytoplankton blooms through controlling the availability of nutrients and light, as well as the dilution of grazers (Sverdrup, 1953; Behrenfeld and Michael 2010). Because of those impacts, it is important to describe MLD variability in the IO and the main processes that control it. While the MLD seasonal variability has been abundantly described, as detailed below, there are fewer studies that investigate its variability at other timescales, and in particular at the omnipresent intraseasonal timescale in the IO (e.g. Goswami, 2005; Zhang, 2005). The objective of this study is thus to describe intraseasonal MLD variability in the IO, as well as the associated climate modes and driving processes, using a combination of observations and model experiments.

Numerous studies have already investigated the patterns and mechanisms of seasonal MLD variations in the IO (Rao et al. 1989; McCreary and Kundu 1989; Rao and Sivakumar 2003; Prasad 2004; de Boyer Montegut et al. 2007; Sreenivas et al. 2008) and discussed their biological impact (e.g. Wiggert et al. 2005; Levy et al. 2007; Kone et al. 2009). The amplitude of the seasonal MLD variations is particularly large in the Arabian Sea, reaching up to $30 \mathrm{~m}$ (Figure 1a). The mechanisms driving these variations differ during the southwest and northeast monsoons. The summer monsoon is characterized by a strong southwesterly Findlater jet (Findlater, 1969) along the western coast of the Arabian Sea, which markedly deepens the MLD in the southern central Arabian Sea owing to Ekman convergence. The winter monsoon is characterized by a negative heat flux at the air-sea interface that plays a dominant role in the convective deepening and cooling of the MLD (Rao et al. 1989; Prasanna Kumar and Narvekar, 2005; de Boyer Montegut et al. 2007). As shown on Figure 
1a, the Bay of Bengal (BoB) exhibits weaker seasonal MLD variations of $\sim 10 \mathrm{~m}$ (Gopalakrishna et al. 1988; Rao et al. 1989; Shenoi et al. 2002; Prasad, 2004; Babu et al. 2004; Narvekar and Prasanna Kumar, 2006), especially in its northern part where strong salinity stratification prevents convective cooling. Finally, the southwestern tropical IO also exhibits large seasonal MLD variations ( 20-30 m; Figure 1a), which have been related to the annual cycle of the wind, through both its stirring effect and impact on buoyancy fluxes, and to thermocline depth (Foltz et al. 2010).

As depicted by Keerthi et al. (2013) using both an ocean model and in-situ observations, the IO is also home to very significant MLD fluctuations at interannual timescales. They showed that the MLD interannual variability is typically of $\sim 10 \mathrm{~m}$ (Figure 1b), about two to four times smaller than the seasonal cycle (Figure 1a), except in the eastern equatorial IO and along the Sumatra and Java coast. Aside from coastal and subtropical regions where eddy-related small-scale structures dominate interannual MLD variations, Keerthi et al. (2013) found that a large fraction of IO MLD interannual variations could be related to large-scale climate modes. The Indian Ocean Dipole, a mode of interannual variability intrinsic to the tropical IO and arising from a positive feedback between the ocean and atmosphere (e.g. Saji et al. 1999), explains most of the MLD interannual variability close to the equator. The Subtropical Indian Ocean Dipole, a large-scale mode of SST variability that apparently arises from atmospheric forcing in the subtropical southern IO (Behera and Yamagata 2001), largely controls large-scale winter MLD variations in the southern IO. In contrast, while El Niños in the neighbouring Pacific Ocean drive SST fluctuations in the IO through zonal shifts in the Walker circulation (e.g. Klein et al. 1999), MLD variations related to El Niño and interannual variations of the summer monsoon appear to be rather weak in the IO. Buoyancy fluxes appear to dominate interannual MLD fluctuations in most of these regions, with wind stirring and Ekman pumping only playing a role in a few regions.

The tropical IO is also home to very clear atmospheric intraseasonal variability, which arises from the interaction between atmospheric large-scale dynamics and deep atmospheric convection. Fluctuations in deep atmospheric convection, rainfall, surface winds and air-sea fluxes within the 30-90 days frequency band develop as the result. This variability is dominated by the northward propagating active and break phases of the monsoon in summer (e.g. Goswami, 2005), and by the eastward propagating Madden Julian Oscillation (MJO, e.g. Zhang, 2005) in winter. Those phenomena have strong regional consequences, for instance impacting agriculture (e.g. Gadgil, 2003; Ingram et al. 2002), modulating the occurrence of tropical weather systems and cyclones (e.g. Webster and Hoyos, 2004; Bessafi and Wheeler, 
2006) or influencing the IO chlorophyll variability (e.g. Resplandy et al. 2009; Jin et al. 2012).

Many studies have identified strong intraseasonal SST fluctuations in response to the aforementioned atmospheric signals in the IO for both winter (Harrison and Vecchi, 2001; Duvel et al 2004, Vialard et al. 2008; Vialard et al. 2013) and summer (Sengupta et al 2001; Vecchi and Harrison 2002; Duvel and Vialard, 2007; Vialard et al. 2012). As an illustration, an index of intraseasonal monsoon activity proposed by Goswami (2005) and detailed in Section 2.4 reveals two strong intraseasonal convective perturbations from July to September 2000 (Figure 2a): these perturbations are associated with large SST variations of $\sim 0.8^{\circ} \mathrm{C}$ in the BoB (Figure 2b). Similarly, a strong MJO event in January-February 1999 as depicted by the Wheeler and Hendon (2004) index detailed in Section 2.4 (Figure 2d) was found to force a peak-to-peak intraseasonal SST perturbation of $\sim 1{ }^{\circ} \mathrm{C}$ south of the equator (Figure 2e; Harrison and Vecchi, 2001; Duvel and Vialard, 2007). It is important to understand the processes responsible for these SST variations because they appear to feed back onto the atmospheric intraseasonal variability (e.g., Maloney and Sobel, 2004; Matthews, 2004; Bellon et al. 2008; Bellenger and Duvel, 2009).

While SST intraseasonal variability has been extensively studied in the IO, there have only been a handful of studies discussing MLD intraseasonal variations. Yet, those MLD intraseasonal variations are far from negligible. An ocean general circulation model simulation (to be described in detail in the next section) for example suggests that the intraseasonal SST signals in Figure 2b, e are associated with MLD intraseasonal variations ranging from 10 to $20 \mathrm{~m}$ in these regions (Figure 2c, f). Historically, intraseasonal MLD variations have been difficult to estimate from observations due to the scarcity of in situ data. The advent of the ARGO program considerably increased the number of available in situ profiles over the recent decade. Compiling these data, Drushka et al. $(2012,2014)$ estimated a MLD fluctuation of more than $15 \mathrm{~m}$ peak-to-peak in the eastern equatorial IO in response to winter MJO forcing. In contrast to seasonal and interannual timescales, there is however to date no exhaustive description and understanding of the main patterns of intraseasonal MLD variations at the basin scale of the IO. Modelling results from Keerthi et al. (2013), however, suggest that interannual and intraseasonal MLD variations have roughly the same magnitude (around $10 \mathrm{~m}$ ), except along the equator and northern BoB where intraseasonal fluctuations are about twice as large (Figure 1b, c). Intraseasonal MLD variations along the equator are even larger than their seasonal counterpart (Figure 1a,c).

Atmospheric heat flux forcing appears to be the dominant process driving 
intraseasonal SST variability in the BoB in response to active/break phases of the summer monsoon (Waliser et al. 2004; Bellon et al. 2008; Duncan and Han, 2009; Vialard et al. 2012) and south of the equator in response to winter MJO forcing (Duvel and Vialard, 2007; Jayakumar et al. 2011). Much debate however remains about the possible impact of intraseasonal MLD variations on these intraseasonal SST variations. Several studies indeed suggest that a slab ocean model using climatological MLD estimates can reasonably well capture observed intraseasonal SST signals in the southwestern tropical IO (Jayakumar et al. 2011) and northwestern Australian Basin (Vialard et al 2013) in winter, as well as in the northern BoB in summer (Vialard et al. 2012). This suggests that MLD intraseasonal variability does not strongly contribute to SST intraseasonal variability in these regions. Drushka et al. (2012) have shown that intraseasonal MLD variations in the southwestern tropical IO and northwestern Australian Basin regions do not affect intraseasonal SST, but that not accounting for intraseasonal MLD variations in the eastern equatorial IO could result in an overestimation of intraseasonal SST signals by up to $40 \%$ there.

Our aim in the present paper is to investigate intraseasonal MLD fluctuations. To that end, an observational dataset built from Argo data and outputs from an eddy permitting $\left(0.25^{\circ}\right)$ regional ocean general circulation model will be used to describe the main large-scale patterns of intraseasonal MLD variations in the IO. We will also show that these MLD fluctuations are linked with well-known modes of atmospheric intraseasonal variability in most regions (the $\mathrm{MJO}$ in winter and active/break phases of the Indian monsoon during summer), except in the Arabian Sea where more local atmospheric fluctuations related to intraseasonal fluctuations of the Findlater jet in summer and intraseasonal air temperature perturbations in winter explain the large intraseasonal MLD variations there. Our modelling approach will finally allow us to understand the main mechanisms responsible for these MLD variations (buoyancy fluxes vs. wind stirring), and to assess their potential impact on the related SST response. The paper is organized as follows. Section 2 describes the numerical experiments, the observed MLD validation product, as well as the statistical methods used to extract the intraseasonal signals. In Section 3, we describe the patterns of intraseasonal MLD variability in the model and observations for both summer (Section 3.1) and winter (Section 3.2), and relate them to atmospheric variability. Model analysis and sensitivity experiments are further used to discuss the respective control of wind-driven mixing and buoyancy fluxes on MLD intraseasonal fluctuations (Section 4.1) and their impact on intraseasonal SST signals (Section 4.2). The last section provides a summary and discussion of our results. 


\section{Data and Methods}

This section describes the observational and modelling tools used in the present study. Section 2.1 describes the model configuration and reference experiment along with the sensitivity experiment used to disentangle the respective influence of buoyancy fluxes and wind stirring on these MLD fluctuations. Section 2.2 describes the processing used to infer intraseasonal MLD variations from Argo data and the datasets used to describe the associated atmospheric variability. The filtering and composite analysis methods are described in Sections 2.3 and 2.4 .

\section{1. Modelling tools}

The model configuration used here is based on the NEMO ocean general circulation modelling system (Madec 2008) and is an IO sub-domain from the global $0.25^{\circ}$ resolution (i.e. cell size $\sim 25 \mathrm{~km}$ ) coupled ocean/sea-ice configuration described by Barnier et al. (2006). The African continent closes the western boundary of the domain. The oceanic portions of the eastern, northern and southern boundaries use radiative open boundaries (Treguier et al. 2001), constrained with a 150-day timescale relaxation to 5-day-average velocities, temperature and salinity from an interannual global $0.25^{\circ}$ simulation (Dussin et al. 2009), using a similar atmospheric forcing as the regional simulation detailed below. This simulation is a product of the DRAKKAR hierarchy of global configurations (Drakkar Group 2007) and has been extensively validated in the tropical Indo-Pacific region (Lengaigne et al. 2012; Keerthi et al. 2013; Nidheesh et al. 2013).

The model starts from World Ocean Atlas temperature and salinity climatologies (Locarnini et al. 2010) at rest and is forced from 1990 to 2007 with the Drakkar Forcing Set \#4 (DFS4, Brodeau et al. 2010) which consists of a modified version of the CORE dataset (Large and Yeager, 2004). In this forcing dataset, ERA40 reanalysis (Uppala et al. 2005) and European Centre for Medium-Range Weather Forecasts (ECMWF) analysis after 2002 are used to compute latent and sensible heat fluxes. Radiative fluxes are based on corrected International Satellite Cloud Climatology Project-Flux Dataset (ISCCP-FD) surface radiations (Zhang et al. 2004) and precipitation forcing consists of a blending of several products proposed by Large and Yeager (2004), including two of the most widely used datasets: the global precipitation climatology project (GPCP, Huffman et al. 1997) and the Climate 
Prediction Center Merged Analysis of Precipitation (CMAP, Xie and Arkin, 1997). All atmospheric fields are corrected to avoid temporal discontinuities and remove known biases (see Brodeau et al. 2010 for details). This experiment successfully reproduces the observed boreal summer intraseasonal SST variations along the coasts of India (Nisha et al. 2013) and boreal winter intraseasonal SST variations in the thermocline ridge region and Northwest Australian basin (Vialard et al. 2013). A more detailed description of the reference experiment can be found in Nisha et al. (2013) and Vialard et al. (2013).

The MLD is controlled by air-sea fluxes of both momentum and buoyancy. Momentum fluxes drive vertically sheared currents, thereby inducing upper ocean mixing and modulating the MLD, while buoyancy fluxes across the air-sea interface modulate the MLD through their stabilizing or destabilizing effect (e.g., Weller and Price, 1988; McWilliams et al., 1997). We hence also perform a sensitivity experiment to evaluate the respective influence of wind stresses and atmospheric buoyancy fluxes in forcing intraseasonal MLD signals in the model. After storing the wind stress computed by the model in the reference simulation, the sensitivity experiment (hereafter NOWIND) is forced by smoothed wind stress that filtered out the intraseasonal component, keeping the buoyancy flux forcing identical to the reference simulation. This sensitivity experiment is run over the same 1990-2007 period from the same initial condition as in the reference experiment.

\section{2. Observed datasets}

As in Drushka et al. (2012), observed MLD signals are derived from Argo profiles downloaded from the Global Ocean Data Assimilation Experiment (GODAE) database. To avoid erroneous MLD estimates, profiles with less than five measurements within the top $100 \mathrm{~m}$ as well as without measurements in the top $6 \mathrm{~m}$ were discarded. As in Drushka et al. (2012), MLD for each profile was calculated as the depth at which density exceeds density at a $6 \mathrm{~m}$ reference depth by $0.05 \mathrm{~kg} / \mathrm{m}^{3}$. Modelled MLD is calculated online using a $0.01 \mathrm{~kg} / \mathrm{m}^{3}$ criterion, lower than the one used in observations because of the absence of a proper diurnal variability in the model (de Boyer Montégut et al. 2004). We also validate the model MLD climatology to the climatology derived from observations by de Boyer Montégut et al. (2004, dBM04).

Typical intraseasonal perturbations of convection, wind, air and SST associated with intraseasonal MLD perturbations will be described using daily data from the National Oceanic 
and Atmospheric Administration $2.5^{\circ}$ resolution gridded Outgoing Longwave Radiation (OLR) product (Liebmann and Smith, 1996), $10 \mathrm{~m}$ winds and $2 \mathrm{~m}$ surface air temperature from ERA-Interim reanalysis data (Dee et al. 2011), windstress data from QuikSCAT scatterometer produced at Centre ERS d'Archivage et de Traitement (CERSAT, Bentamy et al. 2003) and optimally interpolated Tropical Rainfall Measuring Mission Microwave Instrument $0.25^{\circ}$ resolution SST data produced by Remote Sensing Systems (available at www.remss.com).

\subsection{Filtering method}

Intraseasonal signals are isolated using 20 to 110-day filtering based on Fourier transform for all datasets (except MLD Argo-based estimates; see below). Using different filtering methods and different bandpass windows (e.g. 30 to 60 days and 30 to 90 days windows) does not significantly affect our results. In contrast with other data sources in this study, Argo data are unevenly distributed in space and time, and Fourier filtering can therefore not be applied. Intraseasonal signals from Argo data are thus estimated as the difference between the raw signal and a background signal representative of the seasonal and interannual components. This background MLD signal is estimated from the monthly gridded density dataset produced by Roemmich and Gilson (2009), which is based exclusively on Argo profiles and is available from 2004 onward. MLD from this product was then low-pass filtered with a 110-day cutoff and projected onto the exact time and position of each Argo profile using linear interpolation to provide the expected background MLD component for each profile.

In our eddy-permitting simulation, there is a significant amount of meso-scale MLD variability associated with oceanic eddies or other small-scale features. Since we are interested in large-scale MLD variations, the model MLD is filtered in space to retain only large spatial scales $(>250 \mathrm{~km})$. We do this by applying the iterative application of the heat diffusion equation described in Weaver and Courtier (2001), which is well suited to conduct spatial filtering in domains with complex boundaries, like the ocean.

\subsection{Composite analysis}

The sparse and irregular temporal and spatial distribution of Argo profiles does not easily allow mapping MLD variations for individual intraseasonal events. We therefore 
compute composites by averaging all measurements made at a given grid point during a given phase of, for example, the MJO or monsoon active/break cycle, defined using one of the indices described below. The floats provide patchy spatial coverage in some regions, so we restrict our analysis to grid boxes where more than twenty Argo profiles were available for a given phase. Regions where the magnitude of the composite average is smaller than the standard error are masked to highlight the significant patterns of variability. Shaded areas indicate a signal that is coherent across various events, and not merely noise. As shown in the following, both summer and winter intraseasonal MLD variations derived from these composites are of order of $10 \mathrm{~m}$ peak-to-peak but it must be kept in mind that individual MLD events can reach amplitude of up to 30 to $40 \mathrm{~m}$ in all regions discussed below.

We use two well-known indices to define the phases of the main modes of intraseasonal variability in the IO, namely the MJO in winter and the active/break phase of the monsoon in summer. The temporal evolution of the MJO is based on the real-time multivariate MJO indices (RMM1 and RMM2) proposed by Wheeler and Hendon (2004). They correspond to the principal components of a pair of empirical orthogonal functions of the combined fields of near-equatorially averaged $850-\mathrm{hPa}$ zonal wind, $200-\mathrm{hPa}$ zonal wind, and satellite-based outgoing longwave radiation data (see Wheeler and Hendon, 2004 for details). These indices can be used to separate the MJO evolution into eight discrete phases that represent the location of the active MJO as it moves eastward over the IO and through the Pacific Ocean. The RMM1 evolution for the 1999 winter season is shown on Figure 2d as an illustration, with the 8 phases indicated. Composites based on these eight phases (referred to MJO phases in the following) will be used to describe the MLD signals associated to the MJO forcing.

The Wheeler and Hendon (2004) index, however, fails to capture the northward propagation of the monsoon intraseasonal oscillation in boreal summer (Kikuchi et al. 2012). We hence also use a simple index of monsoon active and break phases proposed by Goswami (2005; hereafter Monsoon index) and constructed as the difference between $\mathrm{BoB}\left(70^{\circ} \mathrm{E}-95^{\circ} \mathrm{E}\right.$, $\left.10^{\circ} \mathrm{N}-20^{\circ} \mathrm{N}\right)$ and equatorial $\mathrm{IO}\left(70^{\circ} \mathrm{E}-95^{\circ} \mathrm{E}, 5^{\circ} \mathrm{S}-5^{\circ} \mathrm{N}\right)$ intraseasonal-filtered outgoing longwave radiation (a proxy for atmospheric convection). As illustrated on Figure 2a for the 2000 summer monsoon, we divide this index into six discrete phases that depict the northward propagation of the intraseasonal monsoon spells. Positive and negative parts of the index are each divided into 3 phases of equal duration. As we will show in the following, Phase 2 corresponds to the index maximum and captures the monsoon break phase, while Phases 3 
and 4 correspond to the transition phase from a break to an active phase. Similarly, the index mimimum of Phase 5 captures the monsoon active phase, with Phases 6 and 1 corresponding to the subsequent transition to the break phase.

\section{MLD intraseasonal variability in the IO and its mechanisms}

\subsection{Summer intraseasonal MLD variations}

We will first provide a general overview of the seasonal and intraseasonal MLD variations. We will show that intraseasonal MLD variations in the BoB and eastern equatorial Indian Ocean (EEIO) are related to active/break convective phases of summer monsoon while those in the southern Arabian Sea (SAS) are largely driven by seemingly independent intraseasonal fluctuations of the intensity of the Findlater jet.

\subsubsection{General overview}

The observed June to September (JJAS) climatological MLD and wind stress in the Tropical IO are shown on Figure 3a. The northern IO, BoB and Arabian Sea exhibit contrasted MLD patterns. The mixed layer is deeper in the Arabian Sea (up to $50 \mathrm{~m}$ ), because of the intense Findlater jet that causes both mixing and downwelling to the east of the jet axis (de Boyer Montegut et al. 2007). In contrast, the northern BoB displays a shallower MLD in response to the stabilizing effect of the intense freshwater flux received by this basin during the summer monsoon (Shenoi et al. 2002). South of the equator, the MLD is largely driven by the intensity of climatological winds, with a deeper MLD south of $10^{\circ} \mathrm{S}$ where easterlies are strongest. The model reproduces these large-scale MLD structures reasonably well (Figure 3b). However, the model simulates a shallower MLD than the one inferred from the observational dataset in the coastal regions, which is likely to arise because a lack of Argo profiles in these regions leads to uncertainities in the MLD estimates (Nisha et al. 2013). The model MLD is also shallower along the equator, which cannot be explained by observational coverage but is probably related to a deficiency in either atmospheric forcing or the vertical mixing scheme.

The strongest summer intraseasonal MLD fluctuations are found in the EEIO, where typical MLD variations exceed $15 \mathrm{~m}$ (Figure 3c). Variations of the order of $10 \mathrm{~m}$ are also evident in the BoB, SAS and south of $10^{\circ} \mathrm{S}$. In the BoB and EEIO, these intraseasonal MLD variations occur over regions of relatively shallow climatological MLD (20-40 m) and could 
therefore influence the mixed layer heat budget at intraseasonal timescales. The MLD variability depicted on Figure $3 \mathrm{c}$ can be either the result of large-scale intraseasonal atmospheric forcing or the intraseasonal signature of oceanic meso-scale variations. Contours on Figure 3c show the standard deviation of the model intraseasonal MLD variations after applying a 250-km low-pass filter (discussed in section 2.3). This analysis illustrates that intraseasonal MLD variability in the southwestern Arabian Sea is largely an intraseasonal signature of small-scale variations, most likely related to energetic meso-scale eddies occurring in the Somalia and Oman upwellings (Brandt et al. 2003), with larger-scale variations occurring further east. We will thus focus on the three regions framed on Figure $3 \mathrm{c}$ (the boxes' boundaries are provided in Table 1), where large-scale MLD maxima are found: the BoB, the EEIO and the SAS.

During summer, monsoon active/break phases are the most prominent mode of intraseasonal atmospheric variability. Figure 4a, d maps the percentage of variance of largescale intraseasonal modelled MLD and OLR explained by the Monsoon index: this figure illustrates to which extent this mode drives the MLD fluctuations on Figure $3 \mathrm{c}$ and where this mode is related to large atmospheric convective perturbations at intraseasonal timescales. As expected, this OLR-based index explains a large fraction of atmospheric convection intraseasonal variance in the EEIO and BoB boxes (Figure 4d). Figure 4a further reveals that this index is also able to explain a large fraction of the MLD variance in these two regions. Box-averaged intraseasonal MLD variations in the BoB (resp. EEIO) box indeed display a maximum correlation with the Monsoon index of $-0.74(0.72)$ at 5-day lag. This illustrates that the EEIO and BoB MLD vary out of phase at intraseasonal timescales, under the influence of active/break phases of the summer monsoon as will be discussed in section 3.1.2.

In contrast, the Monsoon index is unable to explain the MLD variations in the SAS box (Figure 4a). Joseph and Sijikumar (2004) report that intraseasonal modulation of the Findlater jet induces strong low-level wind perturbations over the Arabian Sea in summer. We therefore constructed an index based on averaged intraseasonal zonal wind over the SAS box, referred to as the "Jet index" in the following. In contrast to the monsoon index, the Jet index is able to explain a large part of the MLD variance in the SAS (Figure 4b), with a 0.8 correlation between intraseasonal MLD and zonal wind fluctuations averaged over this region. This result illustrates that summer SAS intraseasonal MLD variations are largely driven by intraseasonal wind fluctuations associated with the Findlater jet. The Jet index is not strongly related with the Monsoon index (maximum lag correlation of 0.3 ), suggesting 
that intraseasonal Findlater jet fluctuations in the Arabian Sea are quite independent from convective perturbations. The Jet index indeed only explains up to $30 \%$ of OLR variance along the western coast of India (Figure $4 \mathrm{e}$ ), and $\sim 15-25 \%$ in the BoB where strongest convective perturbations are found in summer. Collectively, the Monsoon and Jet indices explain a large part of MLD variations (50-70\%) in the 3 regions of strongest variability (SAS, BoB and EEIO, Figure 4c, f). In the following, we will use the Monsoon index (i.e. active/break monsoon phase) to describe intraseasonal MLD fluctuations in the BoB and EEIO regions and the Jet index (i.e. enhanced / reduced Findlater Jet) for MLD fluctuations in the SAS region.

\subsubsection{MLD response to active/break phases of the monsoon}

Figure 5 displays the composite patterns of intraseasonal OLR and wind along with modelled and observed intraseasonal MLD for the Monsoon index phases 1 to 4 . The wind and convection patterns (Figure 5a-d) are typical of the evolution from a break to an active phase of the summer monsoon (e.g. Goswami 2005). Phase 1 characterizes the onset of a break phase with weakly supressed convection over the Indian subcontinent and weakly enhanced convection in the equatorial region. Phase 2 is typical of the peak of the break phase, with increased convection (with typical OLR signals of $-20 \mathrm{~W} \cdot \mathrm{m}^{-2}$ ) south of the equator while a tilted band of suppressed convection occupies the northern IO (Figure 5b). The associated wind stress anomaly displayed as contours on Figure $5 \mathrm{f}$ indeed shows a decreased monsoonal wind flow across the SAS and BoB, and increased eastward flow at the equator, as a consequence of the monsoon jet deflection around the southern tip of India. The bands of excess and suppressed convection progress northward during the transition between Phases 3 and 4 (Figure $5 \mathrm{c}-\mathrm{d}$ ), with enhanced convection over the southern part of the BoB and southern India during Phase 4 (Figure 5d). Phases 5 and 6 are almost exactly the opposite of Phases 2 and 3 and are therefore not shown: they characterize a monsoon active phase with an increased monsoon flow and deep atmospheric convection across the Indian subcontinent and northern part of the BoB.

The model MLD response to those monsoon active/break phases is shown on the middle panels of Figure 5, with largest and out-of-phase MLD variations in the EEIO and BoB regions. The main patterns of MLD changes generally agree well with wind stress intensity changes (coutours on the middle panels of Figure 5). MLD anomalies are largest during Phase 3 (and Phase 6, not shown). During Phase 3, increased westerly winds and 
convection in the EEIO result in a MLD deepening of up to $10 \mathrm{~m}$ while reduced monsoonal south-westerly winds and convection in the BoB act to shoal the MLD by up to $7 \mathrm{~m}$ there. In contrast with convective signals, MLD anomalies do not exhibit any clear northward propagation from BoB to EEIO but rather appear as a standing oscillation. In contrast, the Arabian Sea exhibits a weak MLD shoaling signal (up to $2 \mathrm{~m}$ ) that appears to propagate northward from its southern (Phase 1; Figure 5e) to its northern boundary (Phase 4; Figure $5 h)$.

These modelled MLD composites generally agree well with the observed estimates from Argo both in terms of structure and amplitude, except for Phase 2 (Figure 5, lower panels), for which observations do not exhibit the significant signal in the BoB that is seen in the model. Figure $6 \mathrm{a}, \mathrm{b}$ provides more quantitative comparison of the box-averaged composites in regions of largest MLD variations. Consistent with Figure 5, MLD anomalies are out of phase between the EEIO and BoB boxes, with maximum deepening during Phase 3 in the BoB and Phase 6 in the EEIO. Peak-to-peak amplitude of composite MLD signals derived from Argo data reaches $8 \mathrm{~m}$ for the $\mathrm{BoB}$ and EEIO regions. In both regions, the model MLD evolution closely matches the observed one, despite a slight amplitude overestimation in the EEIO region. It must however be noted that the amplitude of individual events can largely exceed those derived from the composite analysis: for example, peak-topeak MLD variations during summer 2000 reached $30 \mathrm{~m}(20 \mathrm{~m})$ in the EEIO (BoB) (Figure 2).

\subsubsection{MLD response to intraseasonal Findlater jet variations}

As discussed above, summer MLD intraseasonal variability also exhibits a clear maximum in the SAS region (Figure 3), associated with intraseasonal modulation of the Findlater jet over the Arabian Sea. Composite patterns of OLR, wind and MLD intraseasonal anomalies associated with the Findlater Jet index are displayed on Figure 7. The upper panels on Figure 7 illustrate the onset (Phase 1; Figure 7a), mature (Phase 2; Figure 7b), decay (Phase 3; Figure 7c) and termination phases (Phase 4; Figure 7d) of intraseasonal pulses of this jet, which are evident in the composite wind field over the SAS. As expected from the weak maximum lag-correlation between Findlater Jet and Monsoon indices (0.3), intraseasonal fluctuations of the Findlater jet are only related to modest convective perturbation over the $\mathrm{BoB}$ (up to $6 \mathrm{~W} \cdot \mathrm{m}^{-2}$ to be compared with the $20 \mathrm{~W} \cdot \mathrm{m}^{-2}$ perturbations related to monsoon active/break phases). Largest convective perturbations (up to $12 \mathrm{~W} \cdot \mathrm{m}^{-2}$ ) 
are found southwest of India during the mature phase of the intensification of this jet (Phase 2; Figure 7b). As already noted by previous authors (e.g. Murtugudde et al. 2007), there are large Ekman pumping signals of opposite phases on both sides of the jet, associated with fluctuations in the jet intensity (most clearly during phases 2-3, see Figure $7 \mathrm{fg}$ ). We will discuss the role of those Ekman pumping perturbations on the mixed layer depth in section 4.

Composite patterns of modelled MLD anomalies related to these phases are provided on Figure 7e-h. Strongest MLD fluctuations occur during phases 2 and 3 in the SAS region, when the jet is most intense (Figure 7b, c), with MLD deepening of up to $7 \mathrm{~m}$ associated with increased winds (Figure 7f, g). MLD signals are weak during the transition phases 1 and 4 (Figure 7e and 7h). The spatial pattern and amplitude of this modelled MLD composite is in broad agreement with the one derived from the observation (Figure 7i-1), where the deepest MLD signals also occur in the SAS region during phases 2 and 3 (Figure 7j, k). Figure 6c provides a more quantitative comparison of the modelled and observed MLD variations in this region. The peak-to-peak amplitude of composite MLD signals derived from Argo data (green line) reaches $12 \mathrm{~m}$. The modelled MLD phase and amplitude reasonably matches the observed one, despite a slight tendency for the model to lead the observed signal.

\subsection{Winter intraseasonal MLD variations}

We will now describe winter intraseasonal MLD variations, and show they mostly occur in the southeastern equatorial Indian Ocean (where they are primarily driven by the Madden Julian Oscillation) and in the northern Arabian Sea (in response to advection of continental air temperature anomalies).

\subsubsection{General overview}

In boreal winter, the Eurasian continent cools and a high-pressure region develops on the Tibetan plateau with resulting north/northeasterly winds over the Arabian Sea (Smith and Madhupratap, 2005; DileepKumar, 2006; Figure 8a, vectors). Though the winds are not as strong as during summer (Figure 3a), they are cold and dry, leading to strong evaporative cooling (Dickey et al. 1998). This buoyancy forcing at the air-sea interface leads to convective mixing and ocean mixed layer deepening in the northern Arabian Sea (Lee et al. 2000; de Boyer Montegut et al. 2007). The MLD remains shallow along the equator and southern IO, due to relatively weak winter winds there. Figure $8 \mathrm{a}, \mathrm{b}$ shows the model is able 
to capture these observed seasonal MLD patterns, despite a slight overestimation in deep MLD regions and underestimation in shallow MLD regions.

Strongest winter intraseasonal MLD variations are found in the southeastern Equatorial IO (SEEIO) and in the northern Arabian Sea (NAS) regions, where the typical MLD amplitude exceeds $10 \mathrm{~m}$ (Figure 8c). MLD fluctuations of about 8m also occur in the BoB. Contours on Figure 8c display the large-scale model MLD variations and illustrate that most of the signal in NAS and SEEIO regions is large-scale, while it is largely mesoscale in the $\mathrm{BoB}$, consistent with previous observational results (Drushka et al., 2014). We will therefore focus our analysis on the NAS and SEEIO regions framed on Figure 8c (see boxes details in Table 1).

The most prominent mode of atmospheric winter intraseasonal variability is the MJO. Figure 9a, d maps the variance percentage of large-scale modelled intraseasonal MLD and OLR fluctuations that can be explained by the MJO index. This index explains 30 to $60 \%$ of OLR variations in the central and eastern IO and 20 to $30 \%$ of intraseasonal MLD variations south of the equator and in the SEEIO box. SEEIO box-averaged intraseasonal MLD has a maximum correlation of 0.5 at lag 0 with the Wheeler and Hendon (2004) MJO index. However, the MJO index explains a weaker percentage of variance than the monsoon index in summer for the BoB and EEIO boxes. A more local wind index (average intraseasonal zonal wind over the SEEIO box) enhances the correlation with MLD variations in the SEEIO region from 0.5 to 0.75 . This local index results in similar MLD patterns to those obtained with the Wheeler and Hendon (2004) MJO index and we therefore decided to illustrate the MLD variations in the EEIO box using this widely used Wheeler and Hendon (2004) MJO index.

The MJO index is unable to explain the strong MLD fluctuations in the NAS region (Figure 9a). At seasonal timescales, strong evaporative cooling associated with cooler and drier air drives the MLD deepening is the northern Arabian Sea (Prasanna Kumar and Narvekar 2005). Hypothesizing that this mechanism also operates at intraseasonal timescales, we constructed an index based on intraseasonal air temperature fluctuations averaged over the NAS box (NAS index), which represents intraseasonal fluctuations of the outbreaks of cold air over the northern Arabian Sea. This index explains a large part of MLD variance in the NAS region (Figure 9b), with a 0.8 correlation between average intraseasonal MLD and air temperature fluctuations over the NAS box. This illustrates that, as for seasonal timescales, intraseasonal winter MLD fluctuations in the northern Arabian Sea are driven by intraseasonal 
air temperature fluctuations. The NAS index is uncorrelated with atmospheric convection anywhere in the IO and is only weakly correlated with the MJO indices (maximum lagcorrelation of 0.2 ), indicating that those air temperature fluctuations are not related to intraseasonal atmospheric convective variations. Drivers of the intraseasonal NAS air temperature variations are discussed below.

\subsubsection{MLD response to the $M J O$}

Figure 10 (top panel) shows the winter MJO typical OLR and wind evolution for suppressed convection over the Indian Ocean. The MJO is associated with eastward propagation of suppressed convective signals in the equatorial IO, with positive OLR and easterly wind anomalies propagating from the western part (Phase 1, Figure 10a) to the eastern part of the IO (Phase 4, Figure 10d). Suppressed MJO conditions are strongest in phases 3 and 4 in the eastern Indian Ocean slightly south of the equator, with positive OLR anomalies of $\sim 15$ W.m-2. Maximum wind anomalies are found south of the equator, where climatological winds are westerly (Figure 8b). Westerly wind anomalies during Phase 1 therefore correspond to an intensification of these climatological westerly winds while easterly wind anomalies during Phase 3 and 4 correspond to a reduction of the climatological westerlies (contours on Figure 10e-f). Phases 5 to 8 are almost exactly the opposite of Phases 1 to 4 and are therefore not shown: they characterize an MJO active phase over the IO with an increased deep atmospheric convection and westerly anomalies south of the equator.

The model MLD response to MJO forcing is largest in the SEEIO region, where MLD shoals during phases 3 and 4 (colors on Figure 10e-f) in response to reduced climatological westerlies (contours on Figure 10e-f) and suppressed convection (Figure 10a-b). Model MLD patterns (Figure 10e-h) generally agree with Argo observations (Figure 10i-1), with a maximum (minimum) MLD in the SEEIO box during Phase 1 (Phase 4). Figure 11a provides a quantitative comparison of modelled and observed MLD intraseasonal variations in this region. The peak-to-peak amplitude of composite MLD signals derived from Argo data (green line) reaches $5 \mathrm{~m}$. The model MLD generally agrees with the observed MLD within the uncertainties, with a slight tendency for the model to lag the observed signal.

\subsubsection{MLD response in the NAS}

We saw earlier that winter intraseasonal MLD variations in the NAS region are strongly related to local air temperature fluctuations. During winter, snowfall and weaker 
solar radiation cools the Asian continent and continental high pressure builds up. This results in northerly winds advecting dry and cold air masses from the continent towards the equator over the IO (de Laat and Lelieveld 2002, Figure 12a). Figure 12b shows a latitude-time section of lag-regressed air temperature over the Arabian Sea and continent to the north of it to air temperature in the NAS box. This figure reveals that air-temperature fluctuations over the NAS region are related to large intraseasonal air temperature fluctuations over northwest India and south Pakistan and propagate southward at $\sim 5$ degrees latitude per day. Mean winds over the continent are relatively weak (Figure 12a). Figure 13 further shows composite maps of temperature and wind anomalies associated with intraseasonal variations of surface air temperature over the NAS. These clearly illustrate that Phases 2-3 correspond to anomalously warm air over the continent and the NAS region and associated southerly wind anomalies. Phases 5-6 (not shown) are associated with anomalies opposite in sign to those in Phases 2-3 and are related to anomalously cold air and northerly wind anomalies in these regions.

These intraseasonal cold air intrusions and related wind fluctuations over the northern part of the Arabian Sea result in large-scale MLD variations. These variations are associated with a positive latent heat flux anomaly (not shown) that shoals the model MLD, with the strongest signals occurring during Phase 2 and 3 (Figure 13f-g). The model MLD signal is consistent with the one derived from observations for Phase 3 (Figure 13k, g) but the insufficient number of observed Argo profiles prevents a proper validation of the signal during Phase 2. Time evolution of the MLD signal in the NAS box agrees well between model and observations, although the model displays a somewhat larger amplitude (Figure 11b).

\section{Related mechanisms and SST impact}

In this section, we will explore the mechanisms driving intraseasonal tropical Indian Ocean MLD variations (Section 4.1) and discuss their potential impact on intraseasonal SST variations (Section 4.2).

\subsection{Mechanisms driving intraseasonal MLD fluctuations}

Our objective in this subsection is to better quantify the processes that control intraseasonal MLD fluctuations in the regions of largest variability in summer (BoB, EEIO 
and SAS) and winter (SEEIO and NAS). The influence of buoyancy fluxes and wind stirring influences can be respectively estimated by calculating surface buoyancy fluxes and the cube of the friction velocity, which are roughly proportional to the amount of energy transferred from the atmosphere to the mixed layer (Niiler and Kraus, 1977). We will use these two parameters to qualitatively infer their respective contribution onto the modelled MLD variations. The net surface buoyancy flux $\mathrm{B}_{\mathrm{o}}$ is computed as follows:

$$
B_{o}=\frac{\alpha Q_{n e t}}{C_{p}}+\beta(P-E) S_{o}
$$

where the first and second terms on the right hand side are respectively the buoyancy fluxes due to heat and fresh water fluxes. $\alpha$ and $\beta$ the coefficients of thermal and haline expansion, $Q_{\text {net }}$ is the net heat flux at the air-sea interface, $C_{p}$ the specific heat capacity of seawater, P-E the net surface fresh water flux and $\mathrm{S}_{\mathrm{o}}$ the surface salinity (Gill 1982). The friction velocity $\mathrm{u}^{*}$ is calculated as:

$$
u^{*}=\sqrt{\frac{\tau}{\rho}}
$$

where $\tau$ is the surface wind stress and $\rho$ the density of seawater. Previous studies (e.g. Murtugudde et al. 2007) indicate that a third mechanism can control MLD in the Arabian Sea in summer. Strong Ekman pumping variations on the southern flank of the Findlater jet (see Figure $7 \mathrm{fg}$ and 14c) can indeed also influence the mixed layer depth by making the thermocline shallower or deeper, and hence stabilizing or destabilizing the ocean column near the bottom of the mixed layer. We verified that significant intraseasonal Ekman pumping variations only occur in the SAS box (i.e. the only box close to the Findlatter jet in summer) and will hence only show Ekman pumping variations for that region (Figure 14c).

Figure 14f-j demonstrates that MLD deepening is associated with both reduced buoyancy fluxes and increased frictional velocity in all regions, except in the NAS where friction velocity variations are negligible. These two forcing mechanisms therefore combine to produce intraseasonal MLD fluctuations in most regions. MLD deepening (resp. shoaling) for all regions except NAS are indeed associated with a wind intensification (resp. reduction) (see contours on middle panels of Figures 5, 7 and 10 and Figure 14, upper panels), which both increases (resp. reduces) the frictional velocity and reduces (resp. increases) the buoyancy fluxes through a modulation of the amplitude of the evaporative cooling (Figure 14, 
middle panels). MLD deepening (resp. shoaling) for all regions except NAS are also associated with an OLR reduction (resp. increase) (see colors on top panels of Figures 5, 7 and 10 and Figure 14, upper panels), which contribute to reduce (resp. increase) the buoyancy fluxes through a modulation of the amplitude of incoming shortwave flux (Figure 14, middle panels). In the NAS region, there is no strong wind variation (see contours on middle panel of Figure 13 and Figure 14e), and hence no wind stirring, but the changes in air temperature drive evaporation and hence buoyancy changes. The non-solar heat flux component (dominated by latent heat flux variations; not shown) significantly contributes to buoyancy flux fluctuations in all regions (Figure 14a-e). Latent heat fluxes dominate buoyancy fluxes fluctuations in the Arabian Sea for winter (NAS box, Figure 14j), due to the modest deep atmospheric convection and surface solar heat flux perturbations associated with MLD variations there (see Figure 9e and Figure 14e). In contrast, summer MLD fluctuations in the BoB and EEIO regions and winter MLD fluctuations in the SEEIO are related to phenomena (MJO and monsoon active/breaks phases) that involve a clear modulation of atmospheric convection (Figure 14a, b, d) and related surface solar flux. As a result, solar heat flux also contributes to buoyancy flux in these regions (Figure 14f, g, and i). Decreased atmospheric convection is generally associated with reduced winds (Figure 14a-e), explaining the in-phase relationship of solar and non-solar heat fluxes contribution to buoyancy fluxes. In the SAS region, the intensification of the Findlater jet is associated with a negative wind stress curl, i.e. wind-driven downwelling (Fig14c) that slightly lags the maximum MLD deepening. These wind stress curl variations probably contribute to the MLD deepening in the SAS region, in addition to the wind stirring and buoyancy effects. This is confirmed by the spatial pattern of the deepening (Figure $7 \mathrm{fg}$ ) that is collocated with the maximum Ekman pumping rather than with the largest wind stress anomalies.

It is difficult to quantify the respective influences of buoyancy fluxes and wind stirring on MLD fluctuations from the above analysis, as these two terms strongly co-vary (see correlations between buoyancy fluxes and frictional velocity on Figure 14f-j). We therefore use the NOWIND sensitivity experiment described in section 2.1 , forced by intraseasonalfiltered wind stress and identical buoyancy flux forcing to the reference simulation. Comparing REF (green line) and NOWIND experiment (dashed green line) on Figure 14k-o therefore allows to quantitatively assessing the respective role of buoyancy fluxes and wind stirring (plus Ekman pumping in the SAS box) on intraseasonal MLD variations. The only region where buoyancy fluxes almost entirely control ( $90 \%)$ intraseasonal MLD fluctuations 
633

634

635

636

637

638

639

640

641

642

643

644

645

646

647

648

649

650

651

652

653

654

655

656

657

658

659

660

661

662

is the NAS box in winter. In the other regions (BoB, EEIO and SAS in summer and SEEIO in winter), the buoyancy fluxes and the wind stirring have a similar contribution, with the contribution from buoyancy fluxes ranging from $45 \%$ in the SAS box in summer to $65 \%$ in the SEEIO box in winter. In these four boxes, MLD fluctuations are associated with similar amplitude buoyancy fluxes signals but frictional velocity fluctuations are comparatively weaker in the equatorial regions (EEIO and SEEIO). This suggests that in these regions, a relatively small wind stress perturbation produces a MLD response that is quite similar to other regions, due to the increased responsiveness of currents (and hence shear and turbulence) to wind in the equatorial waveguide. Finally, it should be noted that for the SAS region (where the largest $\sim 55 \%$ effect of wind stress intraseasonal variations is found), this effect probably results from a combination of wind stirring and Ekman pumping during Findlater jet intraseasonal fluctuations.

\subsection{Impact of intraseasonal MLD fluctuations on SST}

As shown on the bottom panels of Figure 14, the maximum SST warming generally lags the maximum MLD shoaling by $\sim 5$ days. This suggests that MLD variations could influence the SST variations although this influence would be larger if the SST and MLD were in quadrature. Several previous studies (e.g. Jayakumar et al. 2011; Vialard et al. 2012, 2013) have demonstrated the ability of a simple slab ocean model (i.e. fixed MLD) to reproduce intraseasonal SST fluctuations in the IO. We hence assess the impact of intraseasonal MLD variations on intraseasonal SST fluctuations using such a slab ocean described as follows:

$$
\partial_{t} T=\left[\frac{Q_{s}(1-f(-h))+Q^{*}}{\rho C_{p} h}\right]
$$

where T is SST; Qs the surface shortwave flux; Q* the sum of longwave, latent and sensible fluxes; the $\mathrm{f}(\mathrm{z})$ function describes the fraction of shortwave that penetrates down to the depth $\mathrm{z}$ following the double exponential rule corresponding to type I water in the Jerlov (1968) classification; $h$ is the mixed-layer depth; and denotes intraseasonal filtering. We will quantify the importance of intraseasonal MLD fluctuations on SST by applying Eq. (3) for climatological (i.e. without intraseasonal variations) and time-varying MLD.

Figure 15a-e first allows a rough validation of the modelled intraseasonal SST signals 
663

664

665

666

667

668

669

670

671

672

673

674

675

676

677

678

679

680

681

682

683

684

685

686

687

688

689

690

691

692

693

694

695

and the relevance of the slab ocean for modelling it. For all boxes, the model reproduces the observed SST intraseasonal fluctuations well, despite a tendency for the model to underestimate those fluctuations in the EEIO, SAS and NAS regions. The simple slab ocean approach is generally in agreement with the REF experiment (Figure 15a-e), suggesting that heat flux forcing dominates SST intraseasonal variations in these regions, consistent with past studies (e.g. Jayakumar et al. 2011; Vialard et al. 2012, 2013). However, the slab ocean model SST amplitude is larger than in REF experiment in the BoB. In this region, Nisha et al. (2013) indicate that oceanic processes tend to damp SST intraseasonal fluctuations: mixed layer cooling decreases the temperature vertical gradient, hence resulting in reduced cooling by vertical mixing. Despite this negative feedback from oceanic processes in the $\mathrm{BoB}$, heat flux forcing is the first order mechanism that drives SST fluctuations in all the considered regions, justifying our slab ocean approach.

The impact of intraseasonal MLD fluctuations is illustrated on Figure $15 \mathrm{f}-\mathrm{j}$ by comparing slab ocean model SST computed using the actual (blue) and intraseasonal filtered (green) model MLD. Neglecting intraseasonal MLD fluctuations has a minor influence on SST fluctuations in all regions, suggesting that MLD intraseasonal variability does not significantly modulate SST intraseasonal variability (compare green and blue curves on Figure $15 \mathrm{f}-\mathrm{j}$ ). The primary mechanism by which intraseasonal MLD variations can affect intraseasonal SST variations is the modulation of the mixed layer thermal capacity (hereafter "'scaling effect'). However, in regions of shallow mixed layer such as the tropics, a significant part of the incoming solar heat flux penetrates below the mixed layer and therefore does not contribute to mixed layer heating. A small variation of the mixed layer depth can change the amount of heat flux that is "lost" beneath the mixed layer quite significantly (hereafter the "penetrative effect"), because of the exponential nature of shortwave penetration into the ocean. Red curves on Figure $15 \mathrm{f}-\mathrm{j}$ exhibit SST fluctuations derived from the slab ocean model when not accounting for intraseasonal MLD variations when calculating the solar penetration in (3): comparing red and blue curves on these panels allows quantifying the impact of the "penetrative effect" on the amplitude of intraseasonal SST fluctuations. Similarly, brown curves on Figure 15f-j exhibit SST fluctuations derived from the slab ocean model when not considering intraseasonal MLD fluctuations in the denominator of Eq. (3), comparing brown and blue curves on these panels allows the impact of the "scaling effect" to be quantified. Not accounting for the penetrative effect results in overestimated SST intraseasonal amplitude (from $20 \%$ in the BoB to $70 \%$ in the EEIO) for all regions. This is 
because less incoming solar heat is trapped in the mixed layer when the MLD is shallower than normal during the warming phase (and vice versa during the cooling phase), so the penetrative effect damps the SST fluctuations. The impact of the "scaling effect" is more subtle, as it depends on both the sign of the heat flux forcing and the amplitude of the mixed layer depth in each phase. As noted by Shinoda and Hendon (1998) and Drushka et al. (2012), negative net heat fluxes are associated with deep mixed layers (i.e., reduced cooling) and positive heat fluxes with shallow mixed layers (i.e., enhanced warming), so that the scaling effect nearly always induces a relative warming. Because the mixed layer is thinner during the phase with positive heat fluxes, this warming effect is stronger compared to the phase with negative heat fluxes. As a result of this asymmetry, the "scaling effect" results in a SST anomaly with a larger mean (which is filtered out when the intraseasonal variations are extracted) and a larger amplitude. The overall impact of the scaling effect is therefore to amplify SST fluctuations (blue against brown curves on Fig. 15f-j). The compensation between the "scaling" and "penetrative" effects at intraseasonal timescales therefore seems to result in an overall weak impact of intraseasonal MLD fluctuations on intraseasonal SST variations. The slab model approach above is however very simple and its limitations will be discussed in section 5 .

\section{Summary and Discussions}

\subsection{Summary}

The winter MJO and the active and break phases of the summer monsoon are the dominant modes of atmospheric intraseasonal variability in the IO. To date, there was no exhaustive study describing the intraseasonal MLD response to atmospheric intraseasonal variability over the IO. This paper hence aims at a better description of large-scale intraseasonal variability of MLD over the IO. Our study relies on the joint analysis of a dataset built from 2002-2013 Argo data and an eddy permitting $\left(0.25^{\circ}\right)$ regional ocean model, which reproduce observed intraseasonal MLD variations reasonably well.

During the summer monsoon, largest intraseasonal MLD signals are found in eastern equatorial Indian Ocean, Bay of Bengal and southern Arabian Sea. Active and break phases of the summer monsoon drive most of the MLD fluctuations in the eastern equatorial Indian Ocean and Bay of Bengal. During the break phase, enhanced convection south of India is 
associated with a MLD deepening in the eastern equatorial basin, while suppressed convection over the Bay of Bengal results in shallow MLD there. Intraseasonal MLD fluctuations in the southern Arabian Sea are relatively independent from MLD and atmospheric convection variability in the two previous regions. Intraseasonal MLD variations in the southern Arabian Sea are driven by fluctuations of the Findlater jet intensity.

During winter, strongest large-scale MLD variations occur in southeastern equatorial Indian Ocean and in the northern Arabian Sea, while MLD perturbations in Bay of Bengal are mostly small-scale and related to eddy variability. The MLD intraseasonal variability in the southeastern equatorial Indian Ocean is related to MJO forcing, with suppressed convection and light winds associated with shallow MLDs. The southward advection of continental air temperature anomalies induces intraseasonal air temperature fluctuations over the northern Arabian Sea, which drive intraseasonal convective MLD variations.

Buoyancy fluxes and friction velocity both contribute significantly to intraseasonal MLD fluctuations in all regions, except in the northern Arabian Sea in winter, where buoyancy flux forcing dominates and in the southern Arabian Sea in summer, where Ekman pumping on the southern flank of the Findlatter jet also contributes. A slab ocean model analysis suggests that these intraseasonal MLD fluctuations have a weak impact on intraseasonal SST signals in any of the regions (less than $10 \%$ of the amplitude). This weak response is largely explained by the compensation between the "scaling" (i.e. modulation of mixed layer thermal capacity by MLD fluctuations that acts to enhance SST variations) and "penetrative" effects (i.e. modulation of the amount of incoming solar heat flux lost through the base of the mixed layer that has the opposite impact) in our simple framework.

\subsection{Discussion and perspectives}

To our knowledge, Drushka et al $(2012,2014)$ are to date the only observational studies that have described intraseasonal MLD variations in the Indian Ocean, focussing on the MLD response to the MJO in winter in the central and eastern equatorial part of the basin. For this particular region and season, our results echo the observational analysis of Drushka et al $(2012,2014)$, with more than $10 \mathrm{~m}$ peak-to-peak fluctuations in this region. The present study expands this description of the intraseasonal MLD variability for the entire Indian Ocean and for both winter and summer seasons, complementing the analysis of in-situ data with an oceanic simulation. Although model and observationally-derived MLD intraseasonal 
composites exhibit consistent patterns in all the regions of strong intraseasonal variability, the limited density of Argo data did not allow providing a complete mapping of these intraseasonal anomalies. In addition, the use of a composite analysis to extract meaningful MLD variations from observations does not allow monitoring the large event-to-event variability. Future studies with other models and a longer Argo dataset will be needed to ascertain the MLD patterns and amplitudes presented here.

The main goal of this study was to explore MLD variations and their causes in the tropical Indian Ocean. Our results however raise two interesting questions regarding atmospheric variability in the Indian Ocean. Intraseasonal variations in most regions are linked with well-known modes of atmospheric intraseasonal variability: the MJO in winter and active/break phases of the Indian monsoon during summer. On the other hand, MLD intraseasonal variations in the Arabian Sea cannot be clearly connected with a known mode of intraseasonal atmospheric variability. In summer, MLD variations in the southern Arabian Sea are driven by intraseasonal fluctuations of the Findlater jet intensity. Joseph and Sijikumar (2004) already noted changes in the monsoon jet position and intensity linked to active and break phases of the monsoon, which can be seen on Figure 5a-d. In contrast, the wind variations that drive intraseasonal MLD variations in the southern Arabian Sea are upstream (Figure 7a-d), and are independent from monsoon active/break phases and convection over the $\mathrm{BoB}$ and appear to be more driven by convective variability southwest of India (Figure $7 \mathrm{~b}$ and $7 \mathrm{~d}$ ). A more thorough study is needed to assess if this corresponds to a different "flavour" of active/break phase with main convective perturbations over the AS rather than over the BoB, and how the dynamics of this intraseasonal "mode" compare with the more standard active/break phases. Similarly, the occurrence of intraseasonal temperature perturbations over the northern Arabian Sea has to be investigated in more detail. Our results suggest that they are associated with southward advection of continental temperature anomalies by northerly winds. However, the exact nature, process and dominant timescale (if any) of this phenomenon has yet to be understood.

Regarding the potential impact of MLD intraseasonal fluctuations, our slab ocean model results are in line with those of Jayakumar et al. (2011) and Vialard et al. (2012, 2013), which suggested a rather weak influence of intraseasonal MLD fluctuations on intraseasonal SST variations. Our analysis suggests that the "scaling" and "penetrative" effects tend to cancel each other, explaining the overall weak effect of MLD variations on SST. This result apparently contradict those of Drushka et al (2012), which suggests that intraseasonal MLD 
fluctuations may reduce the amplitude of the SST signal during the MJO active phase in the southeastern equatorial Indian Ocean. These differences may well be explained by the very localised SST impact discussed in Drushka et al. (2012), which may be wiped out when averaging over a large region as in the present paper. Alternatively, our results could also be hampered by methodological caveats. First, our assessment using a simple slab ocean model does not account for oceanic processes (lateral advection, entrainment, upwelling). In addition, modelled intraseasonal SST and MLD estimates may suffer from errors inherent to the forcing dataset.

In addition to these methodological caveats, other processes that we did not consider may also influence intraseasonal SST fluctuations. We did not attempt for instance to isolate the contribution of internal oceanic instabilities (e.g. eddies) on large-scale intraseasonal fluctuations. This internally driven variability may indeed constructively/destructively interacts with the intraseasonal variability forced by the large-scale climate modes such as the MJO or the monsoon active/break phases. Jochum and Murtugudde (2005) indeed showed that these small-scale features could significantly contribute to the large-scale SST variations in specific regions of the Indian Ocean. The very intense eddy variability off the Somalia upwelling region may in particular contribute to large-scale upper ocean variations there, as demonstrated by Jochum and Murtuggude (2005). Intraseasonal chlorophyll fluctuations may also alter the vertical profile of solar penetration and hencefore the SST variability. A crude estimate of this effect by including surface chlorophyll variations derived from the satellite data and their impact on the SST of our slab ocean model however suggests that the average impact is very small, although it can be significant for peculiar events (not shown). Finally, scale interaction mechanisms such as the potential rectification of intraseasonal variability onto lower frequency suggested by Waliser et al. $(2003,2004)$ or the potential influence of diurnal cycle onto longer timescales as suggested by Wiggert et al. (2002) may also operate. Addressing such issues would require a more idealized model setup similar to the one used in Waliser et al. $(2003,2004)$ and a properly resolved diurnal cycle, which is lacking in the present model configuration.

Mixed layer depth variability is not only crucial for air-sea interactions and climate but also from a biogeochemical perspective. Mixed layer entrainment and thickness are important determinants of the nutrient flux into the euphotic zone and average light intensity experienced by phytoplankton (McCreary et al. 2001). In the Bay of Bengal, there is a strong coupling between the seasonal cycle of mixed layer depth and the processes that affect upper 
ocean chlorophyll pigment concentrations (Narvekar, 2013). The mixed layer in the central Arabian Sea deepens considerably during both monsoons seasons (McCreary et al. 2001; Wiggert et al. 2005). This gives rise to competing mechanisms that can either lead to a phytoplankton biomass increase or decrease. On the one hand, nutrient concentration increases due to entrainment and grazing-pressure decreases because of a vertically wider habitat, but on the other hand light-limitation increases because of less time spent in the euphotic layer (Levy et al. 2007). Although there have been significant advances in our ability to describe and model the oceanic biogeochemistry in the Indian Ocean, the biogeochemical impact of MLD variations in response to climate variability at intraseasonal timescales in the IO remain largely unknown. Only a handful of studies have examined the ocean ecosystem response to the MJO (e.g. Waliser et al. 2005; Resplandy et al. 2009; Jin et al. 2012). While the MJO drives large intraseasonal chlorophyll signals in the southern IO and in the Bay of Bengal, there are strong intraseasonal chlorophyll fluctuations in the Arabian Sea that only seem to be marginally related to the MJO and whose driving processes remain unclear (Jin et al. 2012). In future, we will use a combination of observations and modelling to investigate the impacts of MLD variations on chlorophyll and primary production in the Arabian Sea.

Acknowledgements. Microwave OI SST data are produced by Remote Sensing Systems and sponsored by National Oceanographic Partnership Program (NOPP), the NASA Earth Science Physical Oceanography Program, and the NASA MEaSUREs DISCOVER Project. Data are available at www.remss.com. Model experiments were performed using HPC resources from GENCI-IDRIS (Grant 2010-011140). Jérôme Vialard and Matthieu Lengaigne are funded by Institut de Recherche pour le Développement (IRD). Matthieu Lengaigne and Marina Lévy contributed to this paper while visiting the National Institute of Oceanography (NIO) in Goa, India. Marina Lévy's visit was supported by TOSCA-CNES. This is NIO contribution number $\mathrm{xxxx}$. 
852

853

854

855

856

857

858

859

860

861

862

863

864

865

866

867

868

869

870

871

872

873

874

875

876

877

878

879

\section{References:}

Babu KN, Sharma R, Agarwal N, Agarwal VK, Weller RA (2004) Study of the mixed layer depth variations within the north Indian Ocean using a 1-D model, J Geophys Res, 109:1-9.

Barnier B, Madec G, Penduff T, Moilnes JM, Treguier AM, Sommer Le, Beckmann A, Biastoch A, Boning C, Deng J, Derval C, Durand E, Gulev S, Remy E, Talandier C, Theetten S, Maltrud M, McClean J, De Cuevas B (2006) Impact of partial steps and momentum advection schemes in a global ocean circulation model at eddy permitting resolution, Ocean Dyn, 56:543-567.

Behera SK, Yamagata T (2001) Subtropical SST dipole events in the southern Indian Ocean, Geophys Res Lett, 28(2): 327-330,doi: 10.1029/2000GL011451.

Behrenfeld, Michael J (2010) Abandoning Sverdrup's critical depth hypothesis on phytoplankton blooms, Ecology, 91(4), 977-989.

Bellenger H, J Duvel (2009) An analysis of tropical ocean diurnal warm layers, J Climate, 22, 3629-3646.

Bellon G, AH Sobel, J Vialard (2008) Ocean-atmosphere coupling in the monsoon intraseasonal oscillation: a simple model study, J Climate, 21, 5254-5270.

Bentamy A, Katsaros KB, Alberto M, Drennan WM, Forde EB, Roquest H (2003) Satellite estimates of wind speed and latent heat flux over global oceans, J climate, 16:637-656

Bessafi, Miloud, MC. Wheeler (2006) Modulation of South Indian Ocean tropical cyclones by the Madden-Julian Oscillation and convectively coupled equatorial waves. Monthly Weather Review, 134.2, 638-656.

Brandt P, Dengler M, Rubino A, Quadfasel D, Schott F (2003) Intraseasonal variability in the southwestern Arabian Sea and its relation to the seasonal circulation. Deep Sea Res II 50:2129-2142

Brodeau L, Barnier B, Treguier AM, Penduff T, Gulev S (2010) An ERA 40-based atmospheric forcing for global ocean circulation models. Science Direct, 31:88-104, doi: 10.1016/j.ocemod.2009.10.005. 
de Boyer Montegut C, Madec G, Fischer AS, Lazar A, Iudicone D (2004) Mixed layer depth over the global ocean : an examination of profile data and a profile-based climatology. J Geophys Res, 109, C12003, doi: 10.1029/2004JC002378

de Boyer Montegut C, Vialard J, Shenoi SSC, Shankar D, Durand F, Ethé C, Madec G (2007) Simulated seasonal and interannual variability of mixed layer heat budget in the northern Indian Ocean, J Climate, 20:3249-3268.

Dee DP, Uppala SM, Simmons AJ, Berrisford P, Poli P, Kobayashi S, Andrae et al (2011) The ERA-Interim reanalysis: Configuration and performance of the data assimilation system. Quarterly Journal of the Royal Meteorological Society, 137(656), 553-597.

de Laat ATJ, J Lelieveld (2002) Interannual variability of the Indian winter monsoon circulation and consequences for pollution levels, J. Geophys. Res., 107(D24), 4739, doi: 10.1029/2001JD001483.

Dickey T, J Marra, DE Sigurdson, RA Weller, CS Kinkade, SE Zedler, JD Wiggert, C Langdon (1998) Seasonal variability of bio-optical and physical properties in the Arabian Sea: October 1994-October 1995, Deep Sea Research Part II: Topical Studies in Oceanography, 45.10 (1998), 2001-2025.

Dileepkumar M (2006) Biogeochemistry of the North Indian Ocean; IGBP-WCRP-SCOPE Rep. Ser.1, Indian Nat.Sci. Acad., New Delhi, India.

Drakkar Group (2007) Eddy-permitting Ocean circulation hindcasts of past decades. Clivar Exchanges 12(3): 8-10, No 42.

Drushka K, Sprintall J, Gill ST (2012) In situ observations of Madden-Julian Oscillation mixed layer dynamics in the Indian and western Pacific Oceans, J Climate, 25.7, 23062328.

Drushka, K., J. Sprintall, and S. T. Gille (2014). Subseasonal variations in salinity and barrier-layer thickness in the eastern equatorial Indian Ocean. J. Geophys. Res. 119, 805-823, doi: 10.1002/2013JC009422.

Duncan B, W Han (2009) Indian Ocean intraseasonal sea surface temperature variability during boreal summer: Madden- Julian Oscillation versus submonthly forcing and processes. J. Geophys. Res., 114, C05002, doi: 10.1029/2008JC004958. 
Dussin R, Treguier A-M, Molines JM, Barnier B, Penduff T, Brodeau L, Madec G (2009) Definition of the interannual experiment ORCA025-B83, 1958-2007, LPO Report 902.

Duvel J-P, Roca R, Vialard J (2004) Ocean mixed layer temperature variations induced by intraseasonal convective perturbations over the Indian Ocean, J. Atm. Sciences 61:1004-1023.

Duvel J, J Vialard (2007) Indo-Pacific sea surface temperature perturbations associated with intraseasonal oscillations of tropical convection. J. Climate, 20, 3056-3082.

Findlater J (1969) A major low level air current over the Indian Ocean during the northern summer, Quart J Roy Meteor Soc, 95:362-380.

Foltz GR, Vialard J, Praveen Kumar B, McPhaden MJ (2010) Seasonal mixed layer heat balance of the southwestern tropical Indian Ocean, J. Climate, 23: 947-965.

Gadgil S, PV Joseph, NV Joshi (1984) Ocean atmosphere coupling over monsoon regions, Nature, 312, 141145.

Gadgil S (2003) The Indian Monsoon and its variability, Annu Rev Earth Planet Sci, 31:429467.

Gill AE (1982) Atmosphere-Ocean Dynamics, Academic Press, 662 pp.

Gopalakrishna VV, Sadhuram Y, Ramesh Babu V (1988) Variability of mixed layer depth in the northern Indian Ocean during 1977 and 1979 summer monsoon seasons, IJMS, 17: 258-264..

Goswami BN (2005) South Asian Monsoon. In: Lau WKM, Waliser DE (eds) Intraseasonal variability in the atmosphere-ocean climate system. Praxis Springer, Berlin, pp 19-55.

Harrison DE, Vecchi GA (2001) January 1999 Indian Ocean cooling event. Geophys Res Lett 28: $3717-3720$.

Huffman GJ, and co-authors (1997) The Global Precipitation Climatology Project (GPCP) combined data set. Bull. Amer. Meteor. Soc., 78, 5-20.

Ingram KT, Roncoli MC, Kirshen PH (2002) Opportunities and constraints for farmers of west Africa to use seasonal precipitation forecasts with Burkina Faso as a case study, 
938

939

940

941

942

943

944

945

946

947

948

949

950

951

952

953

954

955

956

957

958

959

960

961

962

963

964

Jayakumar A, Vialard J, Lengaigne M, Gnanaseelan C, McCreary JP, Praveen Kumar B (2011) Processes controlling the surface temperature signature of the Madden-Julian Oscillation in the thermocline ridge of the Indian Ocean, Clim Dyn, 37, 2217-2234.

Jerlov NG (1968) Marine Optics, Elsevier Oceanography Series, 5.

Jin D, DE Waliser, C Jones, R Murtugudde (2012) Modulation of tropical ocean surface chlorophyll by the Madden-Julian Oscillation, Clim Dyn, 40.1-2, 39-58.

Jochum M, Murtugudde R (2005) Internal variability of Indian ocean SST, J.Climate, 18(18), 3726-3738.

Joseph PV, Sijikumar S (2004) Intraseasonal variability of the low level jet stream of the Asian summer monsoon, J.Climate, 17, 1449-1458.

Keerthi MG, Lengaigne M, Vialard J, de Boyer MC, Muraleedharan PM (2013) Interannual variability of the Tropical Indian Ocean mixed layer depth, Clim Dyn, 40, 743-759.

Kikuchi K, B Wang, Y Kajikawa (2012) Bimodal representation of the tropical intraseasonal oscillation, Clim Dyn, 38.9-10, 1989-2000.

Klein SA, BJ Soden, NC Lau (1999) Remote sea surface temperature variations during ENSO: Evidence for a tropical atmospheric bridge, J Climate, 12: 917-932.

Koné V, O Aumont, M Lévy, L Resplandy (2009), Physical and biogeochemical controls of the phytoplankton seasonal cycle in the Indian Ocean: A modeling study, in Indian Ocean Biogeochemical Processes and Ecological Variability, Geophys. Monogr. Ser., 185, edited by J. D. Wiggert et al., pp. 147-166, AGU, Washington, D. C.

Large WG, Yeager SG (2004) Diurnal to decadal global forcing for ocean and sea-ice models: the datasets and flux climatologies, Techical report TN-460+STR, NCAR, 105 pp.

Lee CM, BH Jones, KH Brink, AS Fischer (2000), The upper ocean response to monsoonal forcing in the Arabian Sea: Seasonal and spatial variability, Deep Sea Res., Part II, 47, $1177-1226$.

Liebmann B, Smith CA (1996) Description of a complete (interpolated) outgoing longwave radiation dataset, Bull. Amer. Meteor. Soc. 77:1275-1277. 
Lengaigne M, Hausmann U, Madec G, Menkes C, Vialard J, Molines JM (2012) Mechanisms controlling warm water volume interannual variations in the equatorial Pacific: diabatic versus adiabatic processes. Clim Dyn 38:1031-1046.

Levy M, D Shankar, JM Andre, SSC Shenoi, F Durand, C de Boyer'Montegut (2007) Basinwide seasonal evolution of the Indian Ocean's phytoplankton blooms, J. Geophys. Res., 112, C12014.

Locarnini RA, Mishonov AV, Antonov JI, Boyer TP, Garcia HE, Baranova OK, Zweng MM, Johnson DR (2010) World Ocean Atlas 2009, vol 1: Temperature. S. Levitus (ed) NOAA Atlas NESDIS 68. U.S. Government Printing Office, Washington, D.C.

Madec G (2008) NEMO, the Ocean Engine. Tech. Rep, Notes de l'IPSL (27), ISSN 12881619, Université P. et M. Curie, B102 T15-E5, 4 Place Jussieu, Paris Cedex 5, p. 193

Maloney E, A Sobel (2004) Surface fluxes and ocean coupling in the tropical intraseasonal oscillation. J. Climate, 17, 3717-3720.

Matthews AJ (2004) The atmospheric response to observed intraseasonal tropical sea surface temperature anomalies, Geophys Res Lett, 31, L14107

McCreary JP, Kohler KE, Hood RR, Smith S, Kindle J, Fischer AS, Weller RA (2001) Influences of diurnal and intraseasonal forcing on mixed layer and biological variability in the central Arabian Sea, J. Geophys. Res Oceans, 106(C4): 71397155.

McCreary JP, Kundu PK (1989) A numerical investigation of sea surface temperature variability in the Arabian Sea, J Geophys Res, 94:16 097-16 114.

McWilliams JC, Sullivan PP, Moeng CH (1997) Langmuir turbulence in the ocean, J. Fluid Mech. 334, 1-30

Murtugudde R, R Seager, P Thoppil (2007) Arabian Sea response to monsoon variations, Paleoceanography, 22, PA4217, doi:10.1029/2007PA001467.

Narvekar J, Prasanna Kumar S (2006) Seasonal variability of the mixed layer in the central Bay of Bengal and associated changes in nutrients and chlorophyll, Deep-Sea Res I, 53: $820-835$. 
Narvekar J, Prasanna Kumar S (2013) Mixed layer variability and chlorophyll a biomass in the Bay of Bengal, Biogeosciences Discuss, 10, 16405-16452.

Nidheesh AG, Lengaigne M, Vialard J, Unnikrishnan AS, Dayan H (2013) Decadal and longterm sea level variability in the tropical Indo-Pacific Ocean, Clim Dyn, 41(2), 381402.

Niiler PP, EB Kraus (1977) One-dimensional models of the upper ocean. Modelling and Prediction of the Upper Layer of the Ocean, E. B. Kraus, Ed. Pergamon press, Oxford, 143-172.

Nisha K, M Lengaigne, VV Gopalakrishna, J Vialard, S Pous, A-C Peter, F Durand, S Naik (2013) Processes of summer intraseasonal sea surface temperature variability along the coasts of India, Ocean Dyn, 63, 329-346.

Prasad TG (2004) A comparison of mixed-layer dynamics between the Arabian Sea and Bay of Bengal: one-dimensional model results, J Geophys Res, 109, C03035.

Prasanna Kumar S, J Narvekar (2005) Seasonal variability of mixed layer in the central Arabian Sea and its implication to nutrients and primary productivity, Deep-Sea Res. II, 52, 1848-1861.

Rao RR, Molinari RL, Festa JF (1989) Evolution of the climatological near-surface thermal structure of the tropical Indian Ocean, J Geophys Res, 94: 1081- 10815.

Rao RR, Sivakumar R (2003) Seasonal variability of sea surface salinity and salt budget of the mixed layer of the north Indian Ocean, J Geophys Res, 108, 3009.

Resplandy L, J Vialard, M Lévy, O Aumont, Y Dandonneau (2009) Seasonal and intraseasonal biogeochemical variability in the thermocline ridge of the southern tropical Indian Ocean, J. Geophys. Res., 114, C07024.

Roemmich D, J Gilson (2009) The 2004-2008 mean and annual cycle of temperature, salinity, and steric height in the global ocean from the Argo program. Prog. Oceanogr., 82 (2), $81-100$.

Saji NH, Goswami BN, Vinaychandran PN, Yamagata T (1999) A dipole mode in the tropical Indian Ocean, Nature, 401, 360-363. 
Schott FA, Xie SP, McCreary Jr JP (2009) Indian Ocean circulation and climate variability, Rev of Geophys, 47, RG1002/2009.

Sengupta D, Goswami BN, Senan R (2001) Coherent intraseasonal oscillations of ocean and atmosphere during the Asian summer monsoon, Geophys Res Lett, 28, 4127-4130.

Shenoi SSC, Shankar D, Shetye SR (2002) Differences in heat budgets of the near-surface Arabian Sea and Bay of Bengal: Implications for the summer monsoon, J Geophys Res, 107, doi 10.1029/2000 JC000679.

Shinoda T, Hendon HH (1998) Mixed layer modelling of intraseasonal variability in the tropical western Pacific and Indian Oceans, J Climate, 11, 2668-2685.

Smith S, M Madhupratap (2005) Mesozooplankton of the Arabian Sea: patterns influenced by seasons, upwelling, and oxygen concentrations, Progress in Oceanography, 65, 2(4), 214-239.

Sreenivas P, Patnaik KVKRK, Prasad KVSR (2008) Monthly Variability of Mixed Layer over Arabian Sea Using ARGO Data, Marine Geodesy, 31, Issue 1, doi: 1080/1490410701812311.

Sverdrup HU (1953) On conditions for the vernal blooming of phytoplankton, J. Cons. Cons. Int. Explor. Mer, 18, 287-295.

Treguier A-M, Barnier B, De Miranda AP, Molines JM, Grima N, Imbard M, Madec G, Messager C, Reynaud T, Michel S (2001) An eddy-permitting model of the Atlantic circulation: evaluating open boundary conditions. J Geophys Res 106:22,115-22,129.

Uppala SM et al (2005) The ERA-40 re-analysis, Q J R Meteorol Soc, 131:2961-3012.

Vecchi GA, Harrison DE (2002) Monsoon breaks and subseasonal sea surface temperature variability in the Bay of Bengal. J Climate, 15, 1485-1493.

Vialard J, Foltz G, McPhaden M, Duvel J-P, de Boyer Montegut C (2008) Strong Indian Ocean sea surface temperature signals associated with the Madden-Julian Oscillation in late 2007 and early 2008, Geophys Res Lett, 35:L19608.

Vialard J, Jayakumar A, Gnanaseelan C, Lengaigne M, Sengupta D, Goswami BN (2012) Processes of 30-90 day sea surface temperature variability in the Northern Indian 
1049

1050

1051

1052

1053

1054

1055

1056

1057

1058

1059

1060

1061

1062

1063

1064

1065

1066

1067

1068

1069

1070

1071

1072

1073

1074

1075

Vialard J, Drushka K, Bellenger H, Lengaigne M, Pous S, Duvel JP (2013) Understanding Madden-Julian induced sea surface temperature variations in the North Western Australian basin, Clim Dyn, 41(11-12), 3203-3218.

Waliser DE, Murtugudde R, Lucas LE (2004) Indo-Pacific Ocean response to atmospheric intraseasonal variability: 2. Boreal summer and the intraseasonal oscillation. J Geophys Res, 109, C03030.

Waliser DE, Murtugudde R, Strutton P, Li JL (2005) Subseasonal organization of ocean chlorophyll: Prospects for prediction based on the Madden-Julian oscillation, Geophys Res Lett, 32(23).

Waliser D, R Murtugudde, L Lucas (2003) Indo-Pacific ocean response to atmospheric intraseasonal variability: 1. Austral summer and the Madden-Julian Oscillation. J. Geo-phys. Res., 108, 3160, doi:10.1029/2002JC001620.

Weaver A, Courtier P (2001) Correlation modelling on the sphere using a generalized diffusion equation, Quart J Roy Meteor Soc, 127:1815-1846.

Webster PJ, C Hoyos (2004) Prediction of Monsoon Rainfall and River Discharge on 15-30 day Time Scales, Bull. Amer. Met. Soc., 85 (11), 1745-1765.

Weller RA, JF Price (1988) Langmuir circulation within the oceanic mixed layer, Deep-Sea Res., 35, 711-747.

Wheeler M, H Hendon (2004) An all-season real-time multivariate MJO index: Development of an index for monitoring and prediction, Mon. Wea. Rev., 132, 1917-1932.

Wiggert JD, R Murtugudde, CR McClain (2002) Processes controlling interannual variations in wintertime (northeast monsoon) primary productivity in the central Arabian Sea, Deep Sea Res., Part II, 47, 2319-2343

Wiggert JD, RR Hood, K Banse, JC Kindle (2005), Monsoon driven biogeochemical processes in the Arabian Sea, Prog. Oceanogr., 65, 176- 213.

Xie P, PA Arkin (1997) Global precipitation: a 17-year monthly analysis based on gauge observations, satellite estimates, and numerical model outputs. Bull. Amer. Meteor. 
Soc., 78, 2539-2558.

1077 Zhang C (2005) Madden-Julian Oscillation, Rev Geophys, 43, RG2003, doi: 10.1029/2004RG000158

1079 Zhang Y, Rossow WB, Lacis AA, Oinas V, Mishchenko MI (2004) Calculation of radiative 1080 fluxes from the surface to top of atmosphere based on ISCCP and other global data 1081 sets: refinments of the radiative trasfer model and the input data, J Geophys Res 109:D19105. doi: 10.1029/2003JD00445

1083

1084

1085

1086

1087

1088

1089

1090

1091

1092

1093

1094

1095

1096

1097

1098

1099 
1101

1102

1103

1104

1105

1106

1107

1108

1109

1110

1111

1112

1113

1114

1115

1116

1117

1118

1119

1120

1121

1122

1123

1124

1125

1126

1127

1128

1129

Figure 1: Standard deviation of MLD variations (in meters) in the Indian Ocean at (a) seasonal, (b) interannual and (c) intraseasonal timescales from a $1 / 4^{\circ}$ simulation provided by the DRAKKAR project detailed in Keerthi et al. (2013). Contours on panel b (resp. panel c) show the ratio of interannual (resp. intraseasonal) against seasonal MLD standard deviation. This figure is adapted from Keerthi et al. (2013).

Figure 2: May to September 2000 time series of (a) intraseasonal summer monsoon active/break index (Goswami et al. 2005) detailed in section 2.4, (b) averaged intraseasonal TMI SST (in ${ }^{\circ} \mathrm{C}$ ) and (c) averaged intraseasonal modelled MLD (in m) over the Bay of Bengal $\left(10^{\circ} \mathrm{N}-20^{\circ} \mathrm{N} ; 80^{\circ} \mathrm{E}-100^{\circ} \mathrm{E}\right)$. December 1998 to April 1999 time series of (d) intraseasonal MJO index (RMM1 from Wheeler and Hendon 2004) detailed in section 2.4, (e) averaged intraseasonal TMI SST (in ${ }^{\circ} \mathrm{C}$ ) and (f) averaged intraseasonal modelled MLD (in $\mathrm{m}$ ) over the thermocline ridge of the Indian Ocean $\left(2^{\circ} \mathrm{S}-10^{\circ} \mathrm{S} ; 60^{\circ} \mathrm{E}-90^{\circ} \mathrm{E}\right)$. The climatological seasonal SST and MLD depth are indicated on the bottom left corner of the corresponding panels. Details on the model simulation from which intraseasonal MLD are calculated are provided in Section 2.1 while intraseasonal monsoon and MJO indices and TMI satellite SST data are detailed in Section 2.2. An illustration of the phase definition for monsoon and MJO indices is also provided on the top panels.

Figure 3: (a) Observed summer climatological MLD (color) from de Boyer Montegut et al 2004 climatology and wind stress (arrows) from Tropflux and (b) Modeled summer (JJAS) climatological MLD (color) and wind stress (arrows). (c) Summer standard deviation of MLD (color) and large-scale MLD (contour) intraseasonal variations. The black boxes indicate regions of maximum large-scale MLD variability, whose boundaries are provided in table 1.

Figure 4: Percentage of summer intraseasonal modelled MLD variance explained by (a) the Monsoon index (Goswami 2005), (b) the JET index (zonal wind averaged over the 
$\left[55^{\circ} \mathrm{E}-75^{\circ} \mathrm{E} ; 2.5^{\circ} \mathrm{N}-12.5^{\circ} \mathrm{N}\right]$ box) and (c) the two previous indices, collectively. (d-f) Same but for intraseasonal OLR variance. Contours on panel $\mathrm{c}$ and $\mathrm{f}$ display the standard deviation of summer intraseasonal large-scale MLD and OLR, respectively. Black boxes indicate the three regions of largest intraseasonal MLD variations, whose boundaries are provided in table 1.

Figure 5: Composites of the phases 1 to 4 of the intraseasonal summer monsoon index from Goswami (2005) for (top) OLR (color) and winds (arrow), (Middle) large-scale model MLD (color) overlaid with large-scale model wind stress intensity anomalies (contours in $10^{-2} \mathrm{~N} . \mathrm{m}^{-2}$ ), (Bottom) Argo MLD. Regions where composite values are less than the standard error are displayed in white. Phases 5 and 6 are almost exactly the opposite of Phases 2 and 3 and are therefore not shown.

Figure 6: Box-averaged composite evolution of model (black) and Argo (green) intraseasonal MLD anomalies for the six phases of the intraseasonal summer monsoon index in the (a) BoB and (b) EEIO boxes. (c) Same but for MLD composites anomalies based on the Findlater Jet index in the SAS box. The error bars represent the standard error.

Figure 7: Composites of phases 1-4 of the intraseasonal Findlater "jet index" of (top) largescale OLR (color) and winds (arrow), (middle) large-scale model MLD (color) overlaid with large-scale model wind stress intensity anomalies (contours in $10^{-2} \mathrm{~N}^{-m^{-}}$ ${ }^{2}$ ) and large scale model wind stress curl (blue contours in $10^{-7} \mathrm{~N} . \mathrm{m}^{-3}$ ), (bottom) Argo MLD (color). Regions where composite values are less than the standard error are displayed in white. Phases 5 and 6 are almost exactly the opposite of Phases 2 and 3 and are therefore not shown.

Figure 8: (a) Observed summer climatological MLD (color) from de Boyer Montegut et al 2004 climatology and wind stress (arrows) from Tropflux and (b) Modeled winter (DJFM) climatological MLD (color) and wind stress (arrows). (c) Winter standard deviation of MLD (color) and large-scale MLD (contour) intraseasonal variations. The 
black boxes indicate regions of winter maximum large-scale MLD variability, whose boundaries are provided in table 1

Figure 9: Percentage of winter intraseasonal modelled MLD variance explained by (a) the MJO index (b) the NAS temperature index (2-m air temperature averaged over the $\left[55^{\circ} \mathrm{E}-75^{\circ} \mathrm{E} ; 15^{\circ} \mathrm{N}-25^{\circ} \mathrm{N}\right]$ box) and (c) the two previous indices. (e-f) Same but for intraseasonal OLR variance. Contours on panel (c) and (f) display the standard deviation of winter intraseasonal large-scale MLD and OLR respectively. Black boxes indicate the boxes used for calculating the winter indices.

Figure 10: Composites of phases 1-4 of the Wheeler and Hendon (2004) MJO index for (top) large-scale OLR (color) and winds (arrow), (Middle) large-scale model MLD (color) overlaid with large-scale model wind stress intensity anomalies (contours in $10^{-2}$ N.m ${ }^{-}$ 2), (Bottom) Argo MLD (color). Regions where composite values are less than the standard error are displayed in white. Phases 5-8 are almost exactly the opposite of phases 1-4 and are therefore not shown.

Figure 11: Box-averaged composite evolution of model (black) and Argo (green) intraseasonal MLD anomalies for (a) the eight phases of the Wheeler and Hendon (2004) index in the SEEIO box and (b) the six phases of the NAS temperature index in the NAS box. The error bars represent the standard error.

Figure 12: (a) Climatological map of DJFM $2 \mathrm{~m}$ air temperature (color) and wind (arrows). (b) Lag-regression of intraseasonal air temperature anomalies zonally averaged between $55^{\circ} \mathrm{E}$ and $75^{\circ} \mathrm{E}$ onto NAS air-temperature index. This box is marked on panel (a). The land-sea limit is marked as thick black line in panel (a).

Figure 13: Composites of phases 1-4 of the intraseasonal NAS winter air temperature index for (top) large-scale near surface air temperature (color) and winds (arrow), (Middle) 
large-scale model MLD (color) overlaid with large-scale model wind stress intensity anomalies (contours in $10^{-2} \mathrm{~N} . \mathrm{m}^{-2}$ ), (Bottom) Argo MLD (color). Regions where composite values are less than the standard error are displayed in white. Phases 5-8 are almost exactly the opposite of phases 1-4 and are therefore not shown.

Figure 14: Lag regression onto the relevent local climate modes of intraseasonal variations of (top) OLR, wind stress module and wind stress curl (only for panel c), (middle) frictional velocity and buoyancy fluxes including the solar and non-solar heat flux component from REF experiment and (bottom) MLD and SST from REF experiment and MLD from NOWIND experiments in the (a, f, k) BoB (Monsoon index), (b, g, l) EEIO (Monsoon index), (c, h, m) SAS (Jet index), (d, i, n) SEEIO (MJO index) and $(\mathbf{e}, \mathbf{j}, \mathbf{o})$ NAS (NAS index). The regression coefficient of the NOWIND on to the REF is indicated on the upper right corner of each panel in (k-o). The correlation between frictional velocity and buoyancy fluxes intraseasonal variations is indicated on the upper right corner of each panel in (f-j).

Figure 15: Lag regression of SST onto the relevent local climate modes: (a, f) BoB (Monsoon index), (b, g) EEIO (Monsoon index), (c, h) SAS (Jet index), (d, i) SEEIO (MJO index) and (e, j) NAS (NAS index). Top panels show SST from TMI (black), REF (purple) and slab ocean model (blue). Bottom panels are for slab ocean model SST (blue) and slab ocean model SSTrecalculated neglecting the impact of intraseasonal MLD variations on the "scaling" effect (brown), the "penetrative" effect (red) or both (green). See text for details.

\section{Table Captions:}

Table 1 : Regions of strong large-scale MLD intraseasonal signals in the Indian Ocean. 

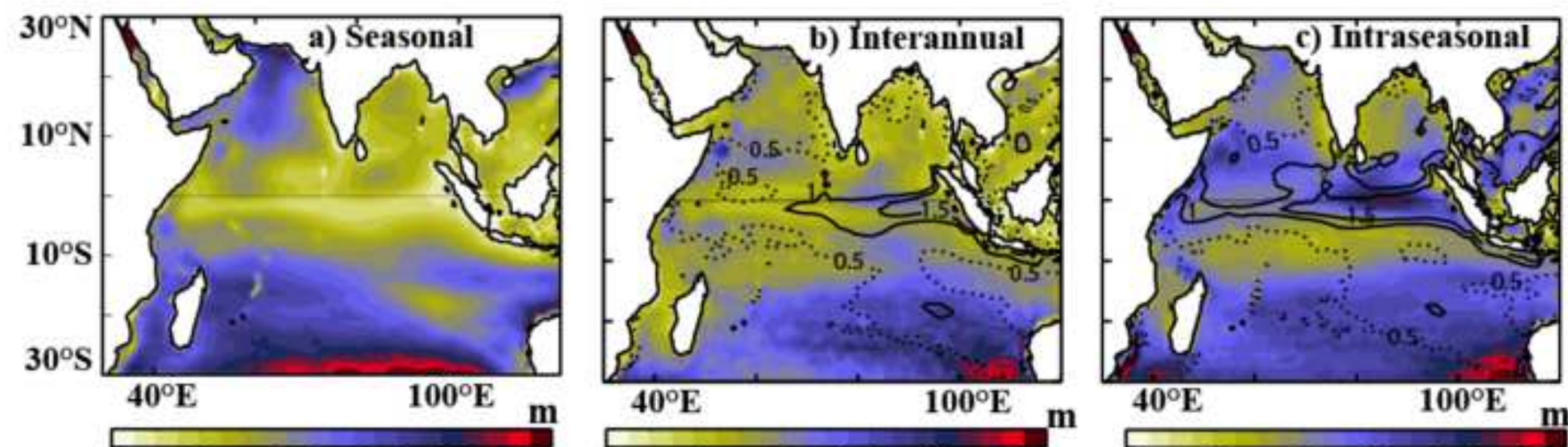

0. 8. 16. 24. 32.40. 2. 5. 8. 11. 14. 17. 2. 5. 8. 11. 14. 17. 
$4|5| 6|1| 2 \mid 3$
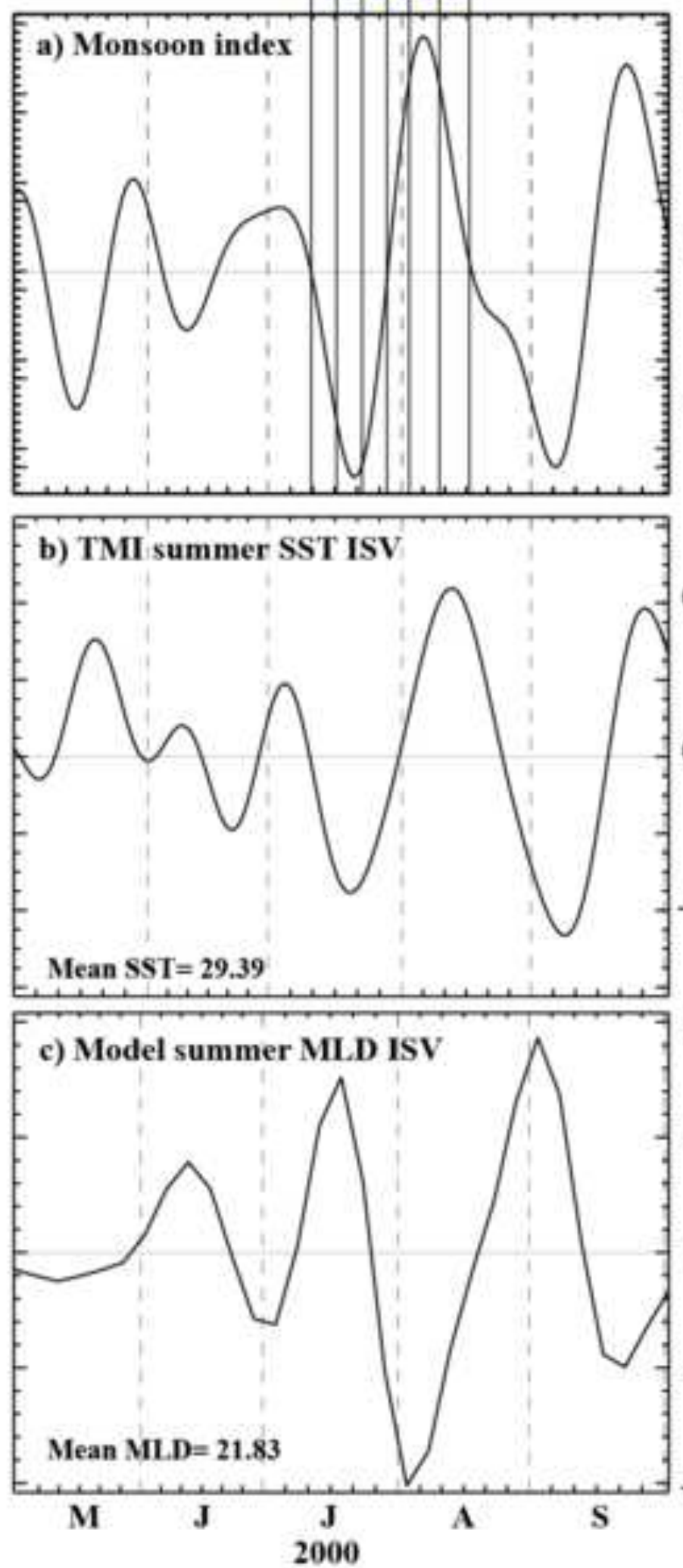

Hatd 6 |7.8

d) MJO index

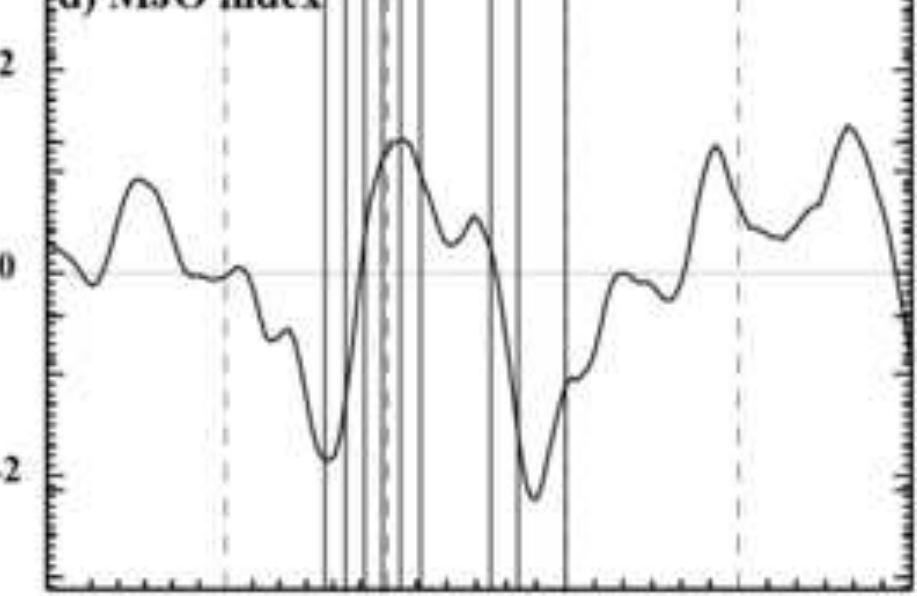

e) TMI winter SST ISV
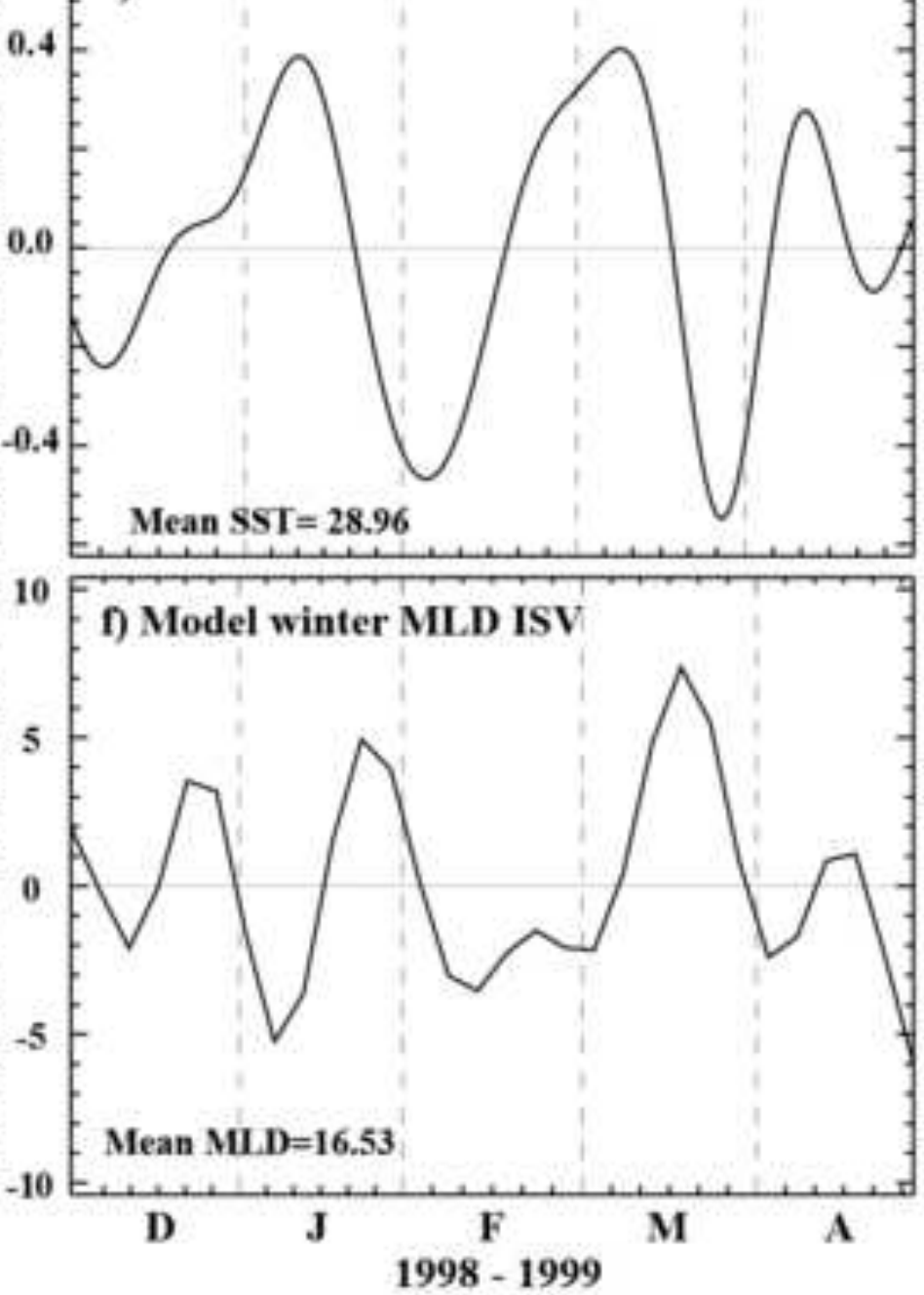

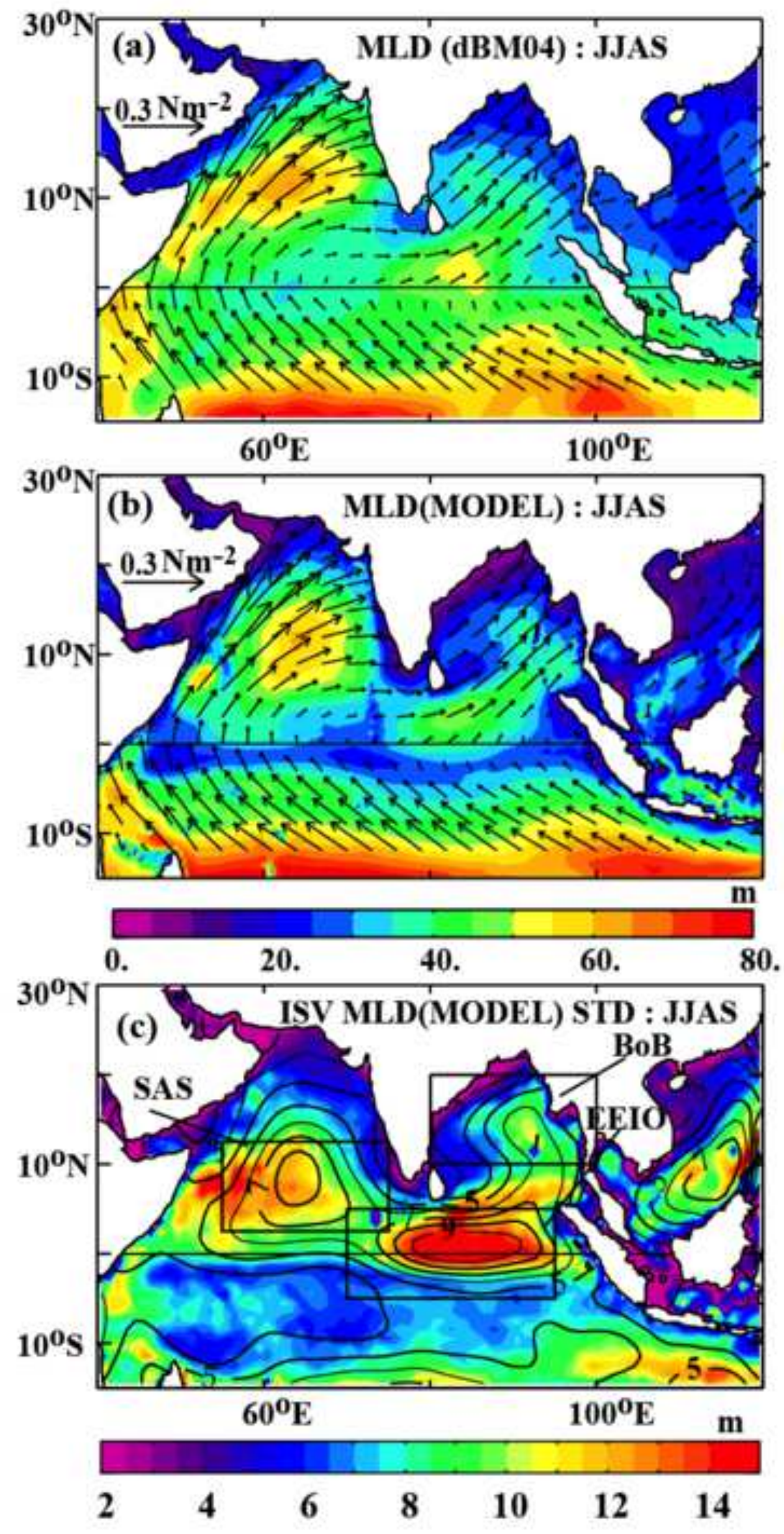

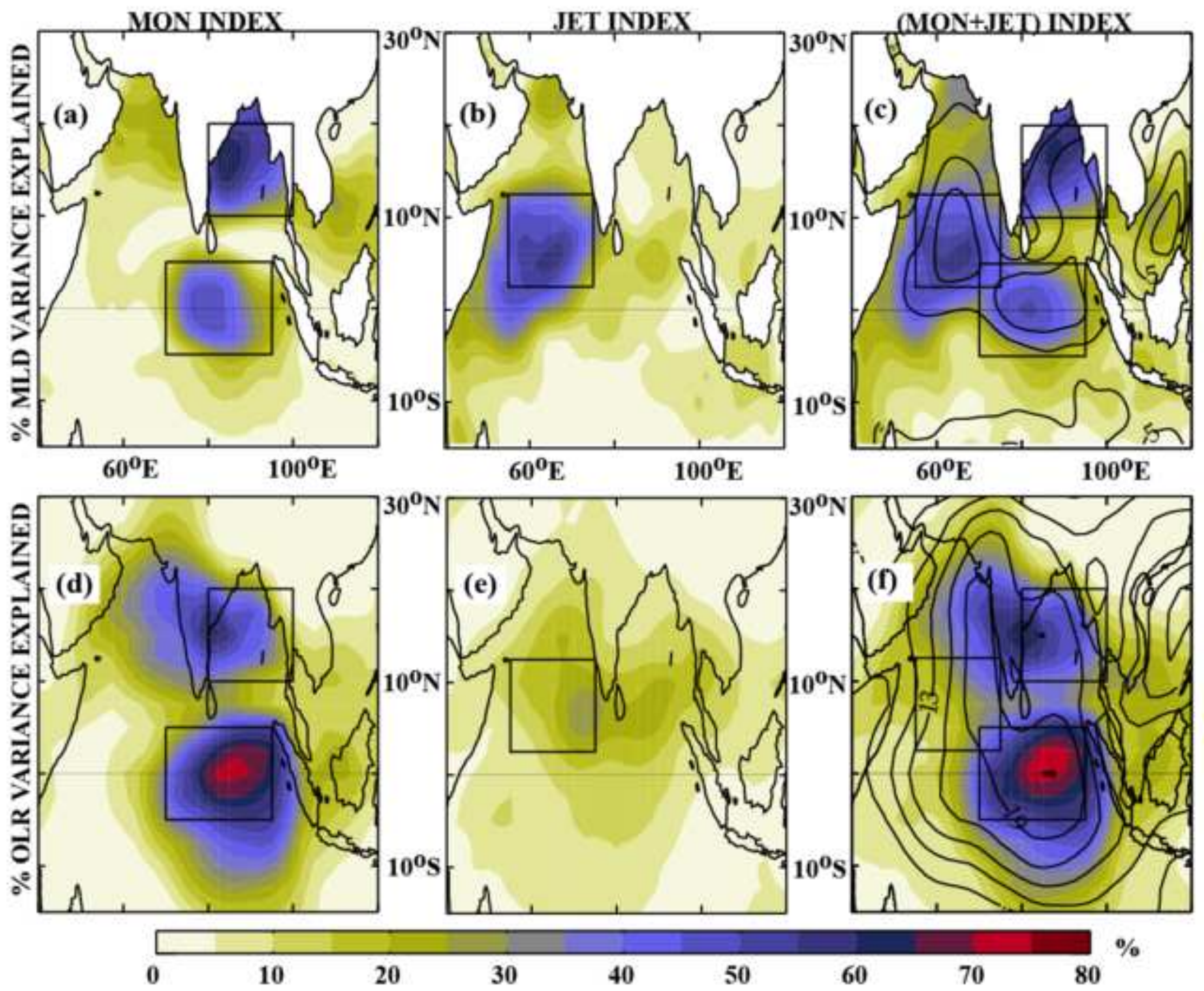

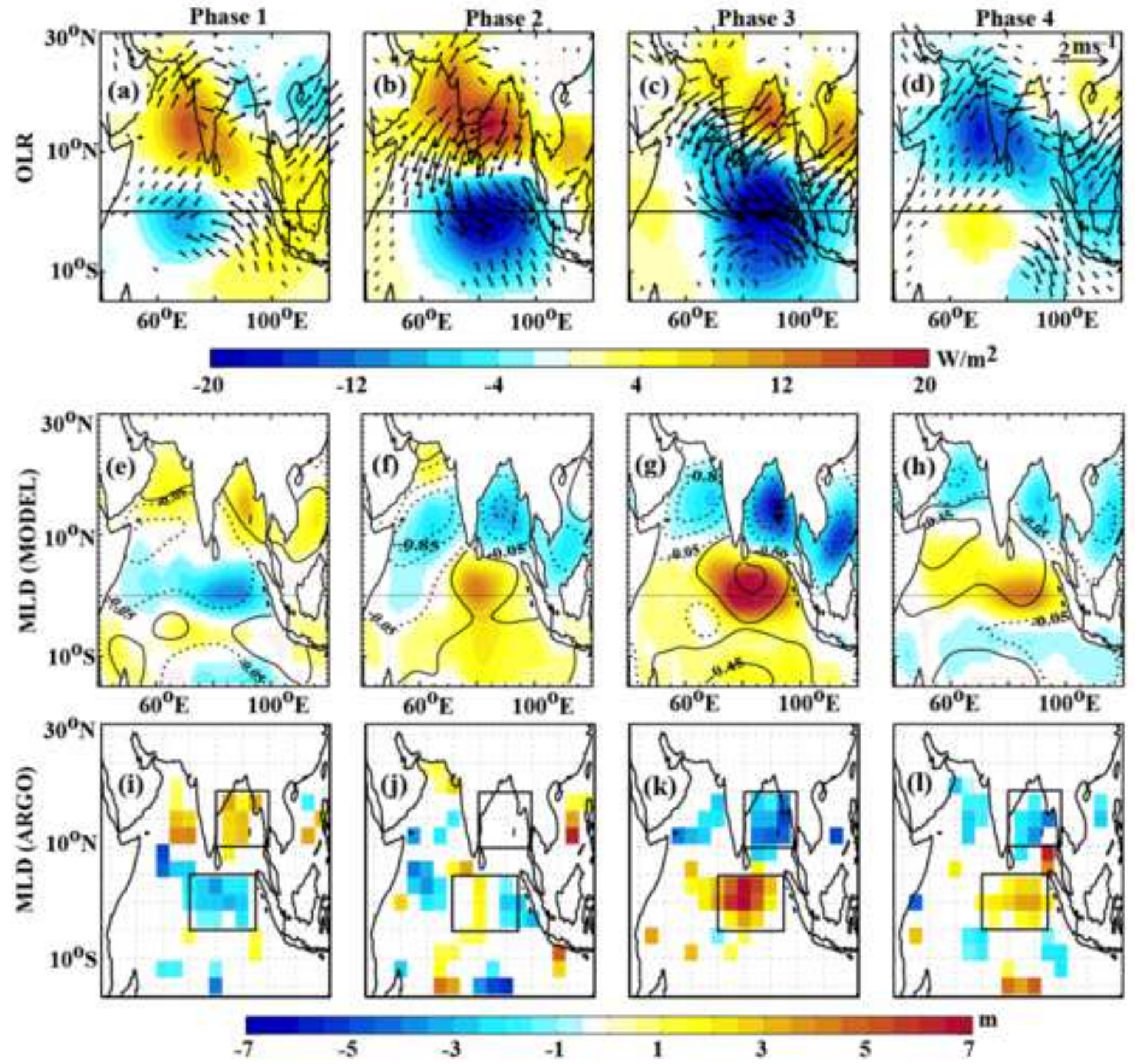

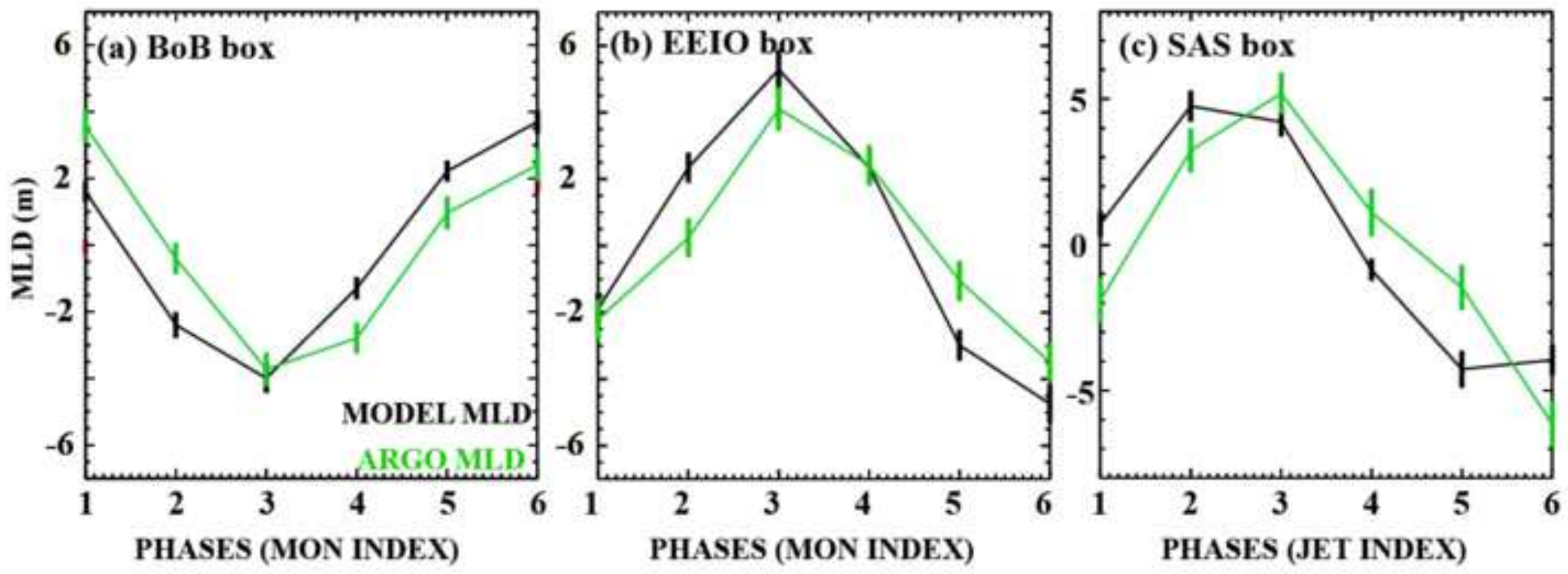

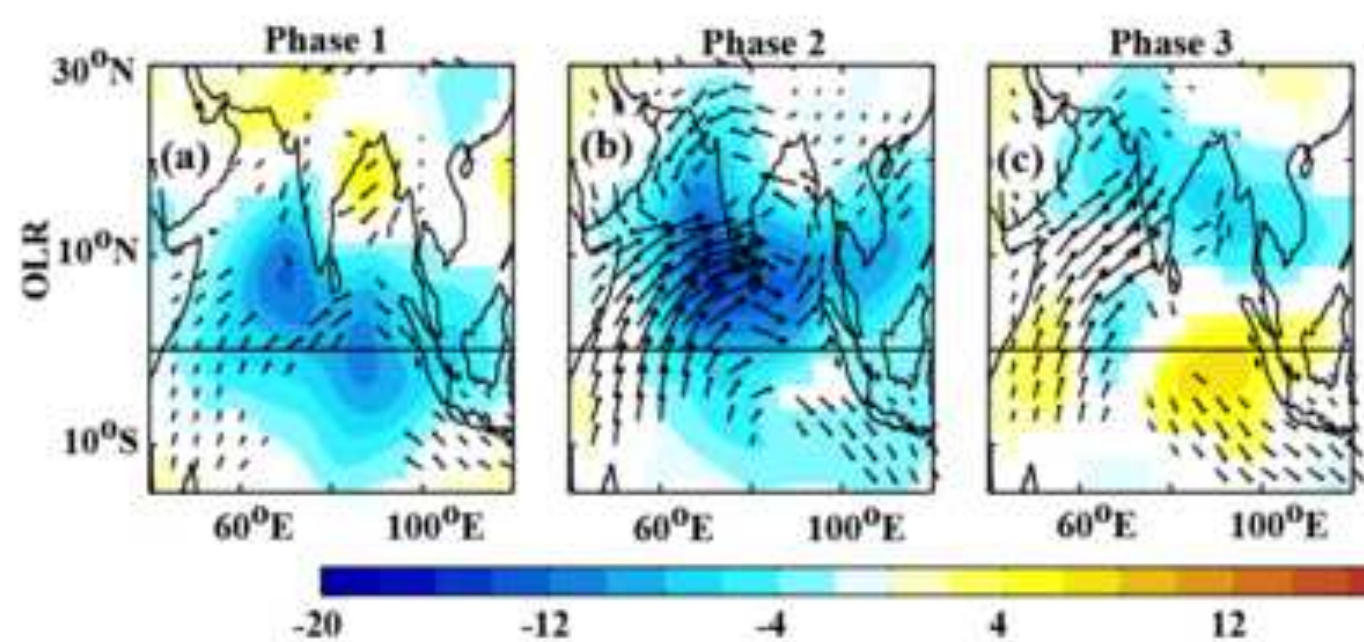

Phase 4
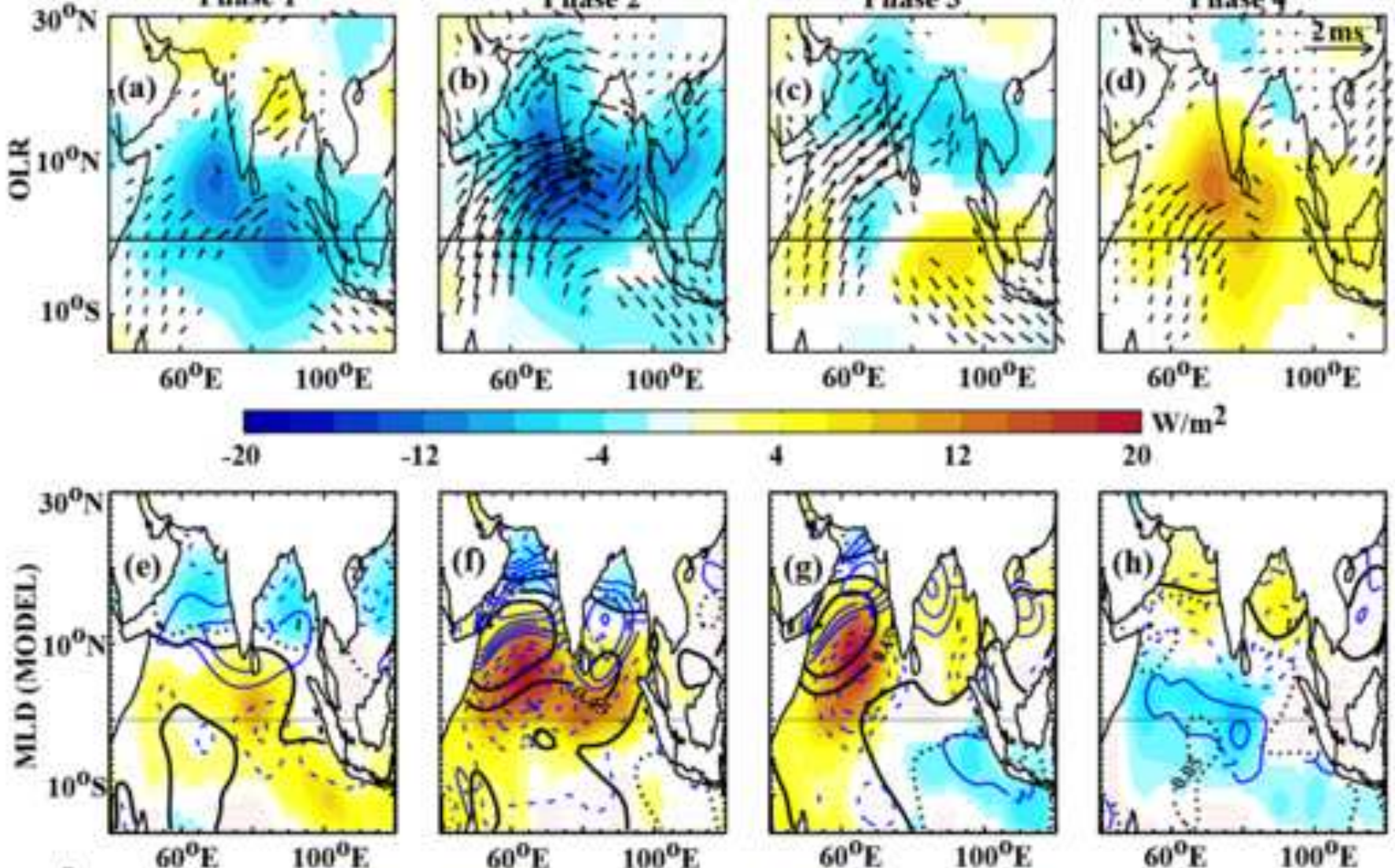

$\mathrm{W} / \mathrm{m}^{2}$
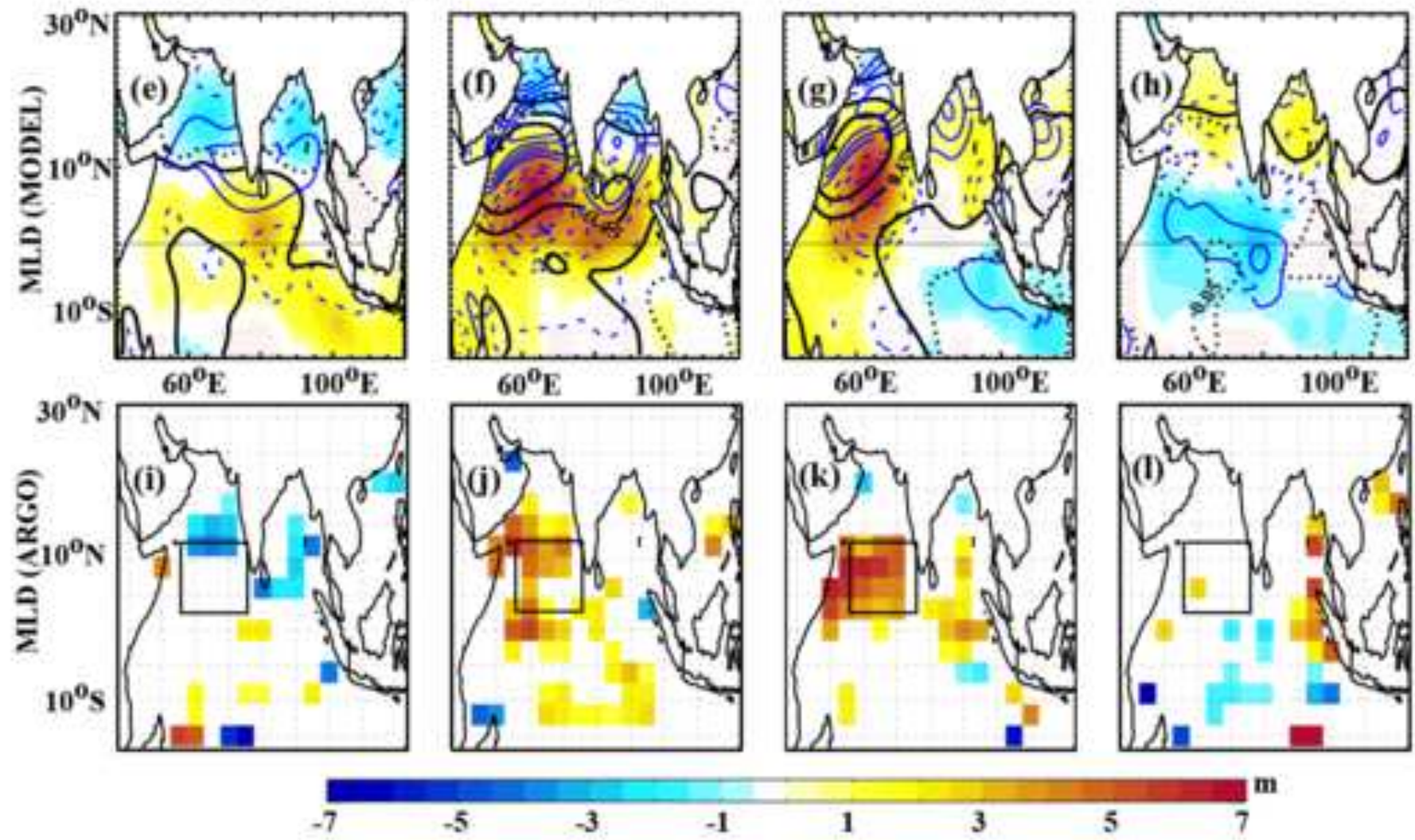

$-5$
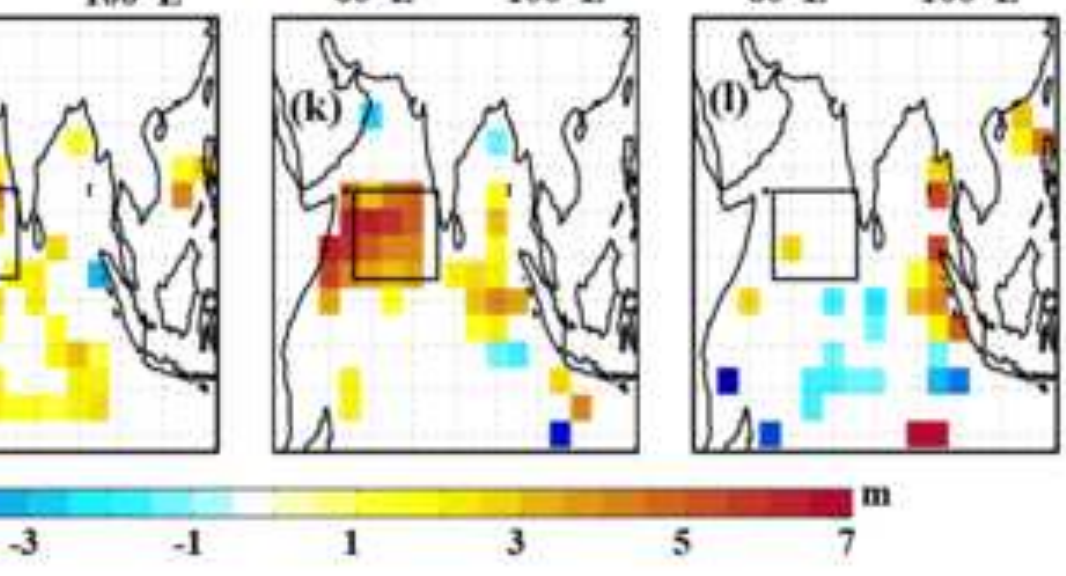

$7^{m}$ 

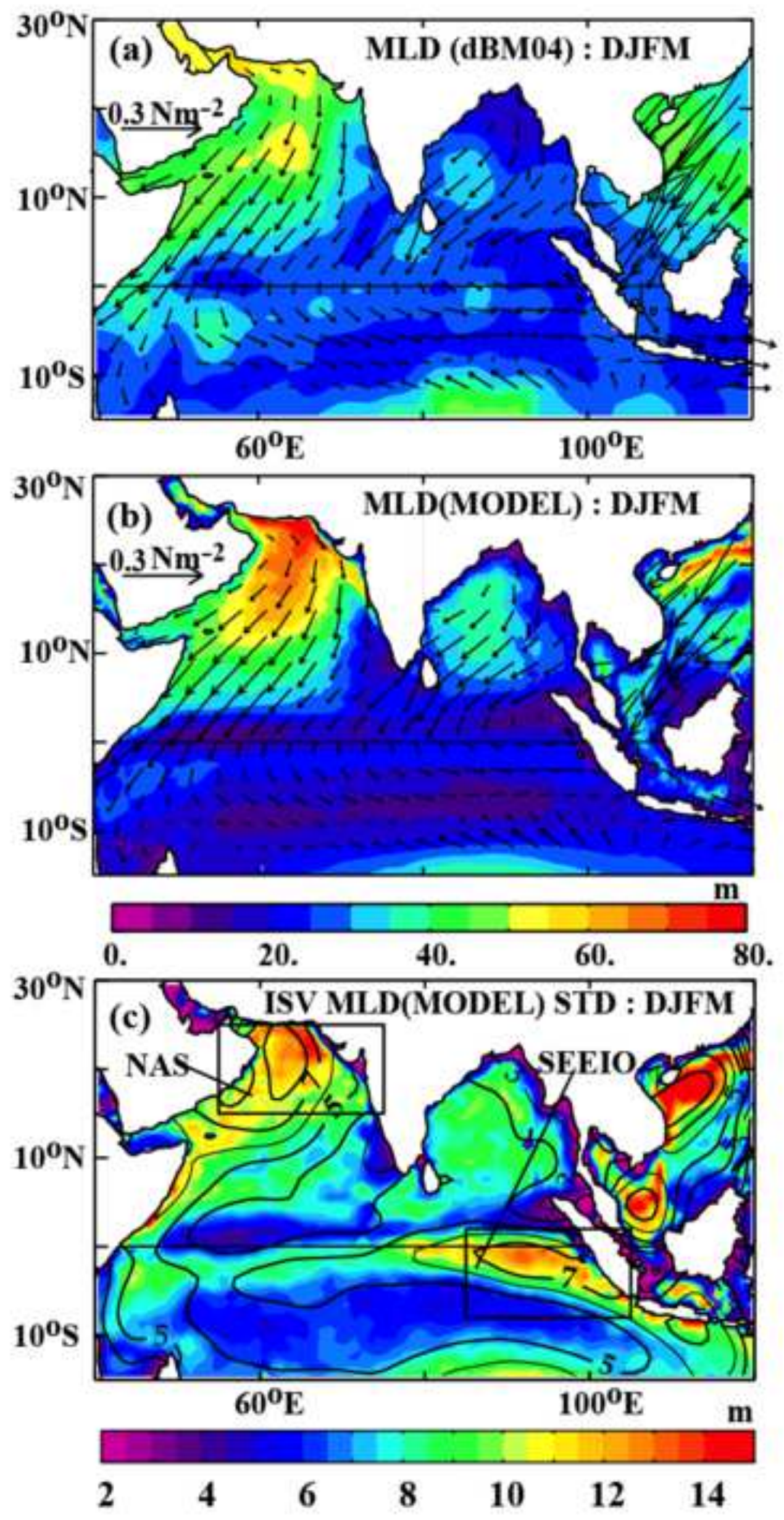

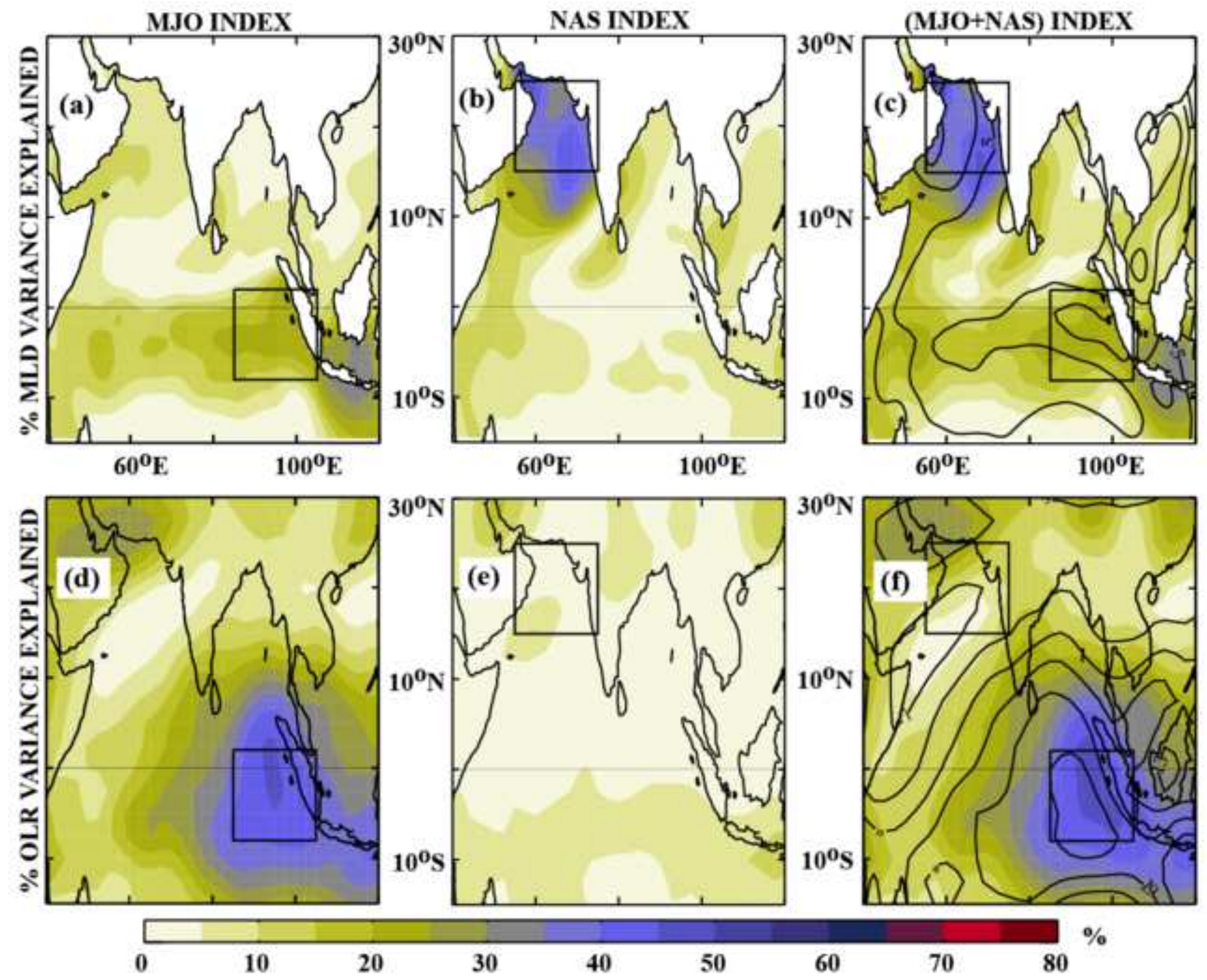
MUO PHASE COMPOSITE.
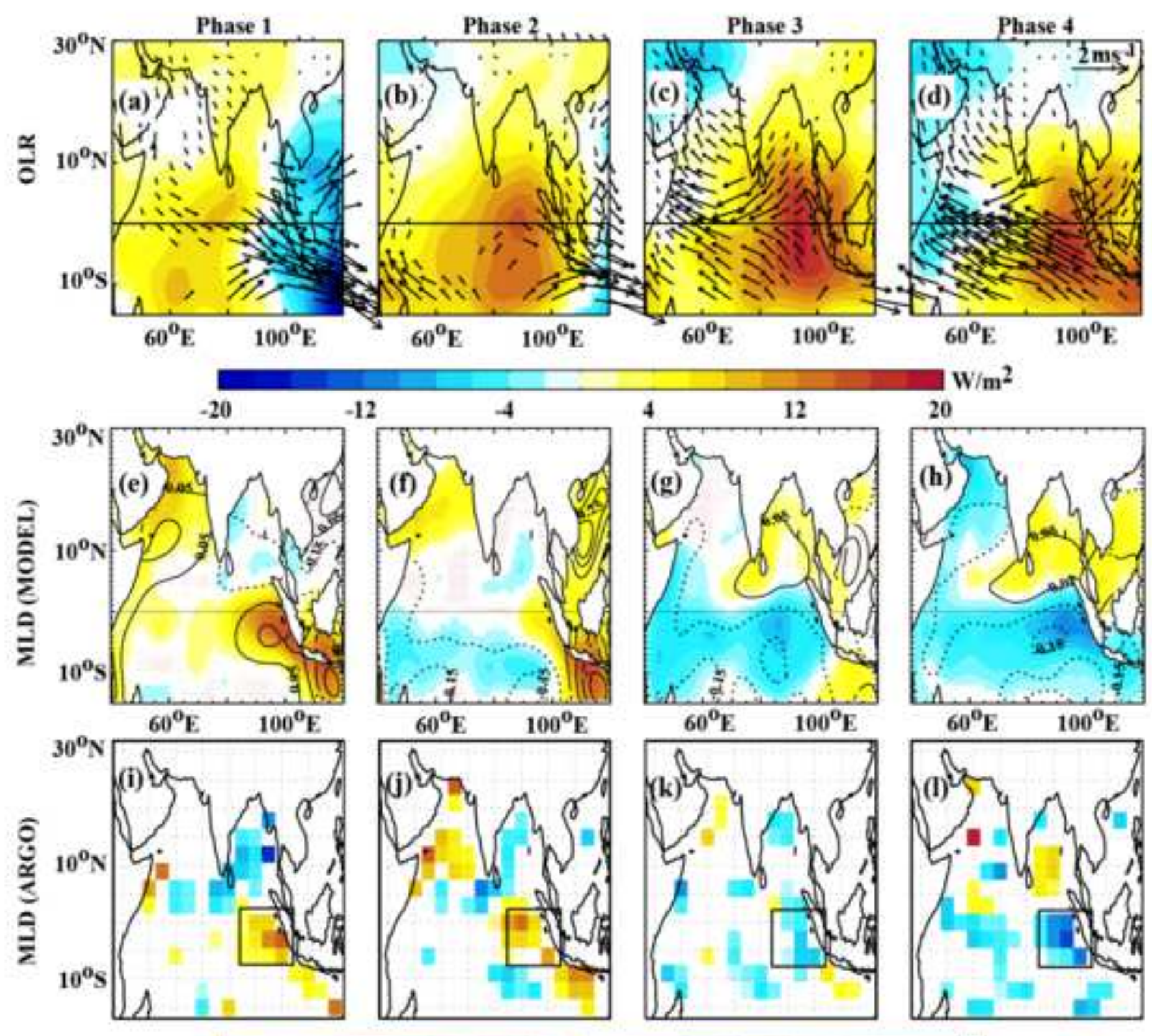

$\mathrm{W} / \mathrm{m}^{2}$
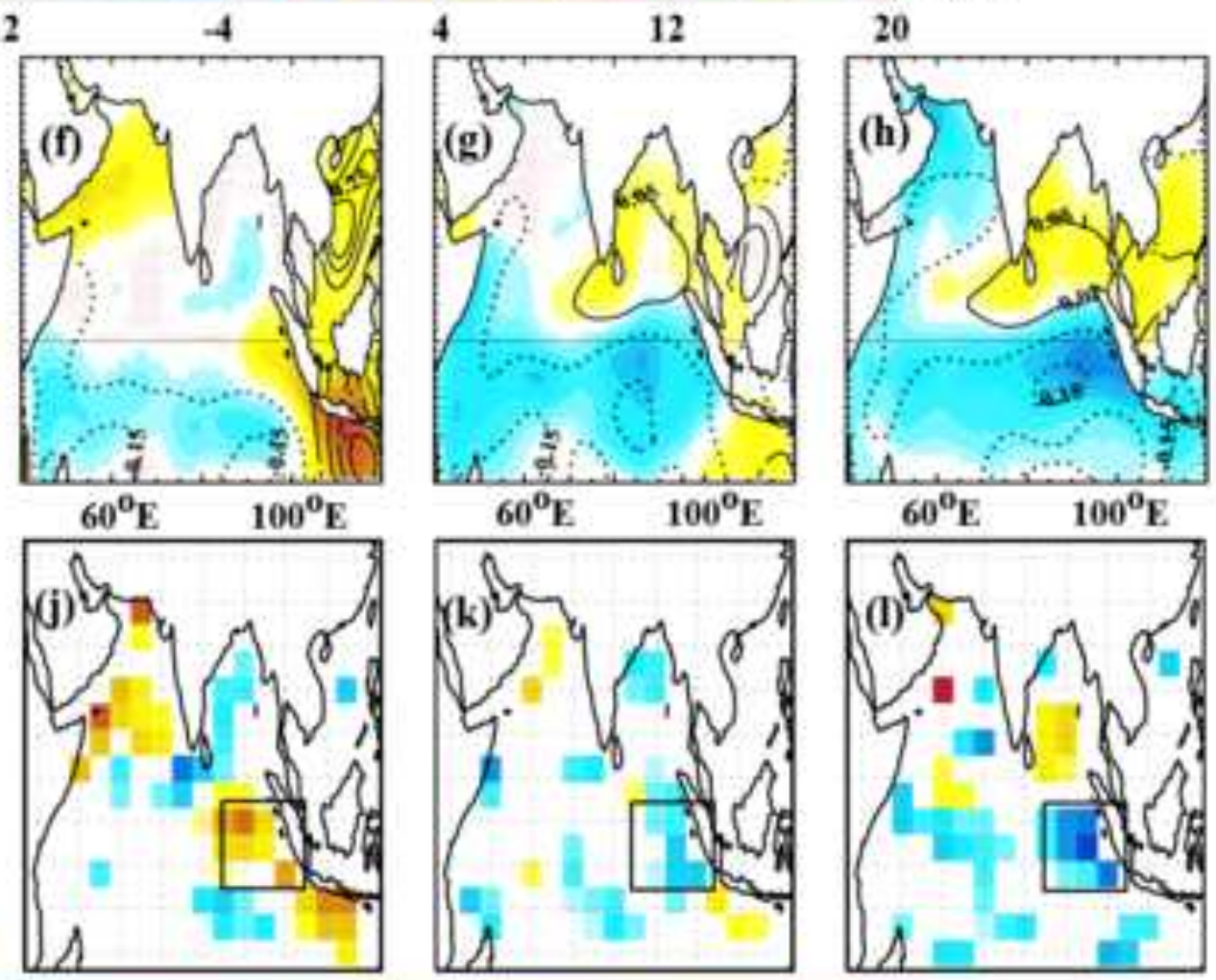

$-7$

$-5$

$-3$
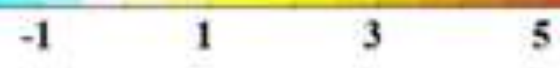


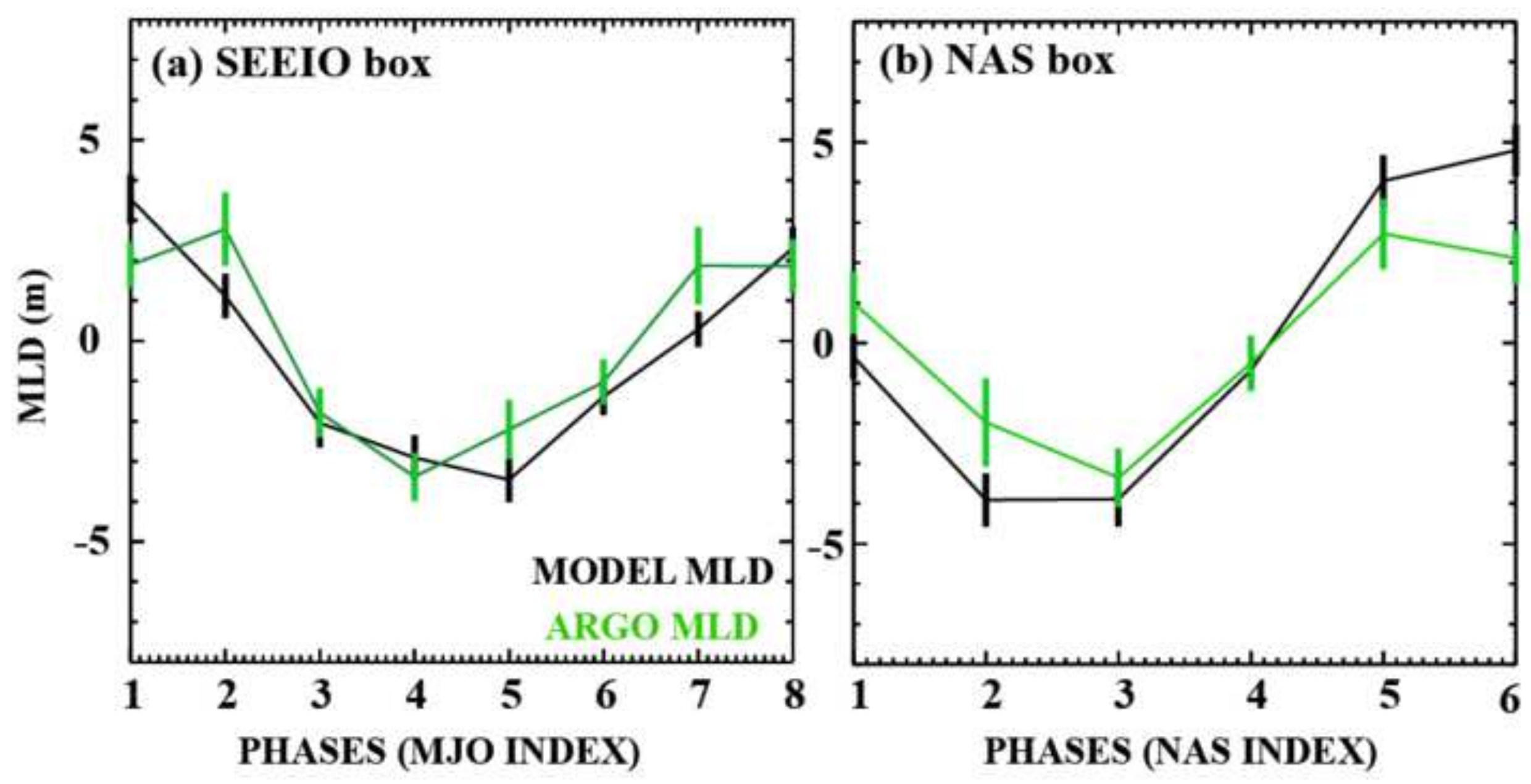


(a) T2 \& 10m WIND : DJFM

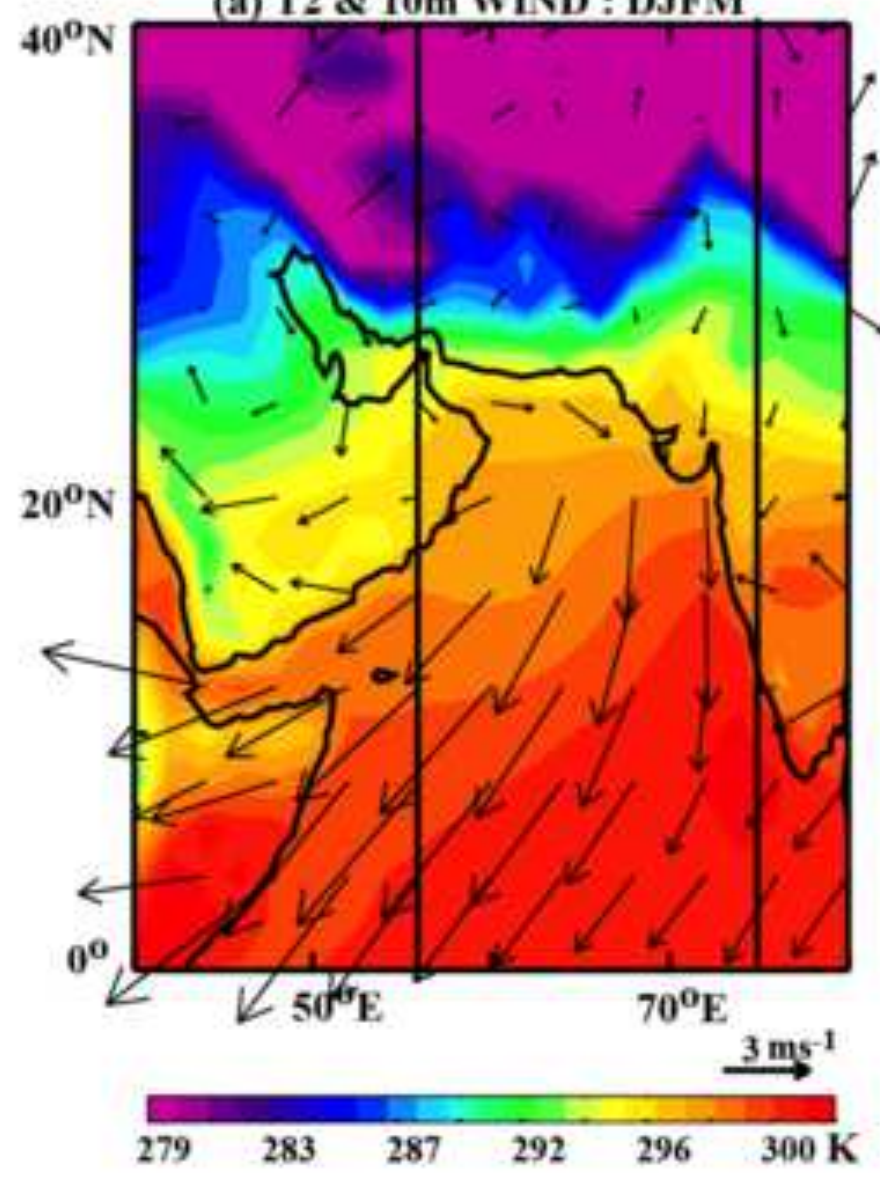

(b) T2 ISV : NAS INDEX

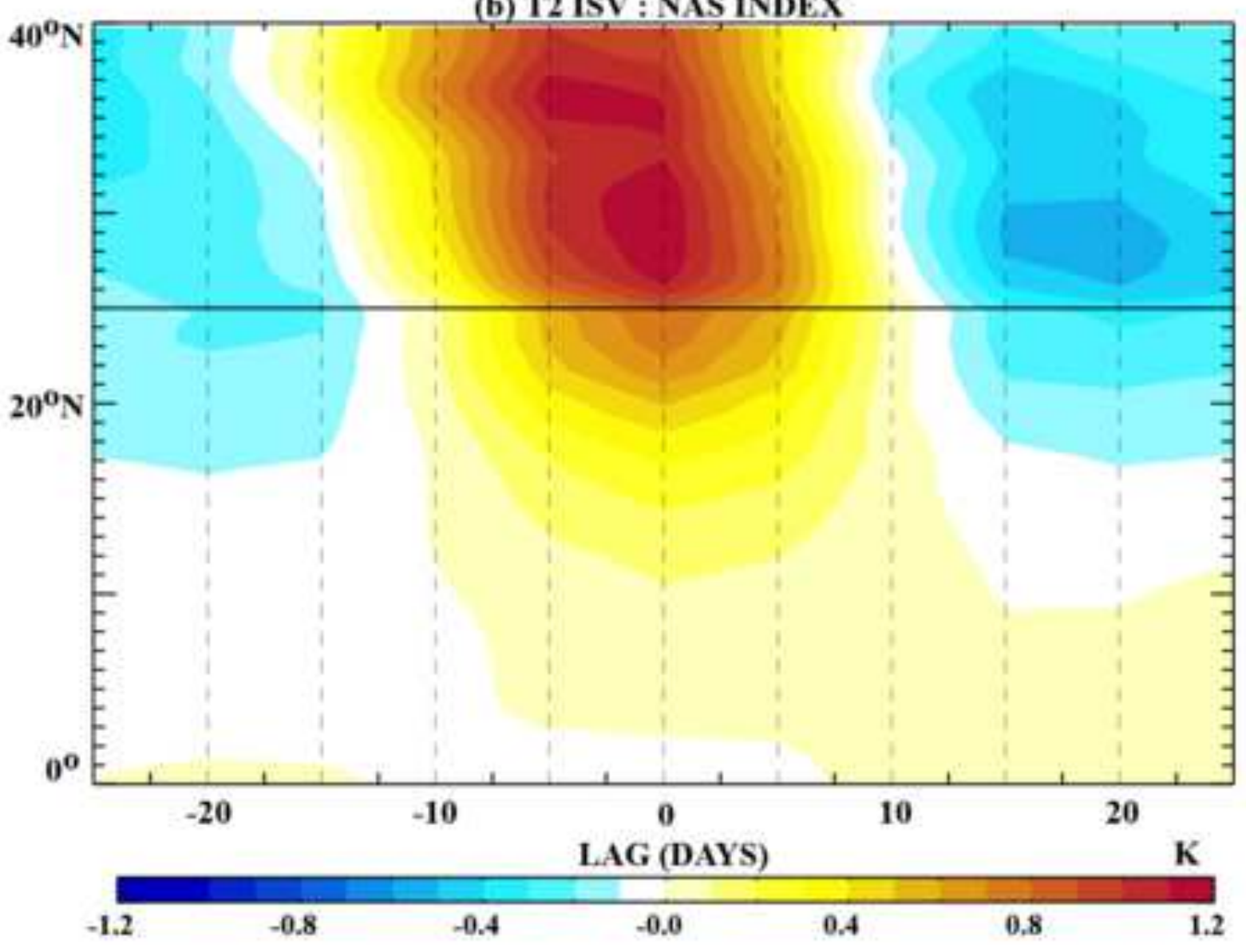




\section{NAS INTRASEASONALEVENT COMPOSIIE}
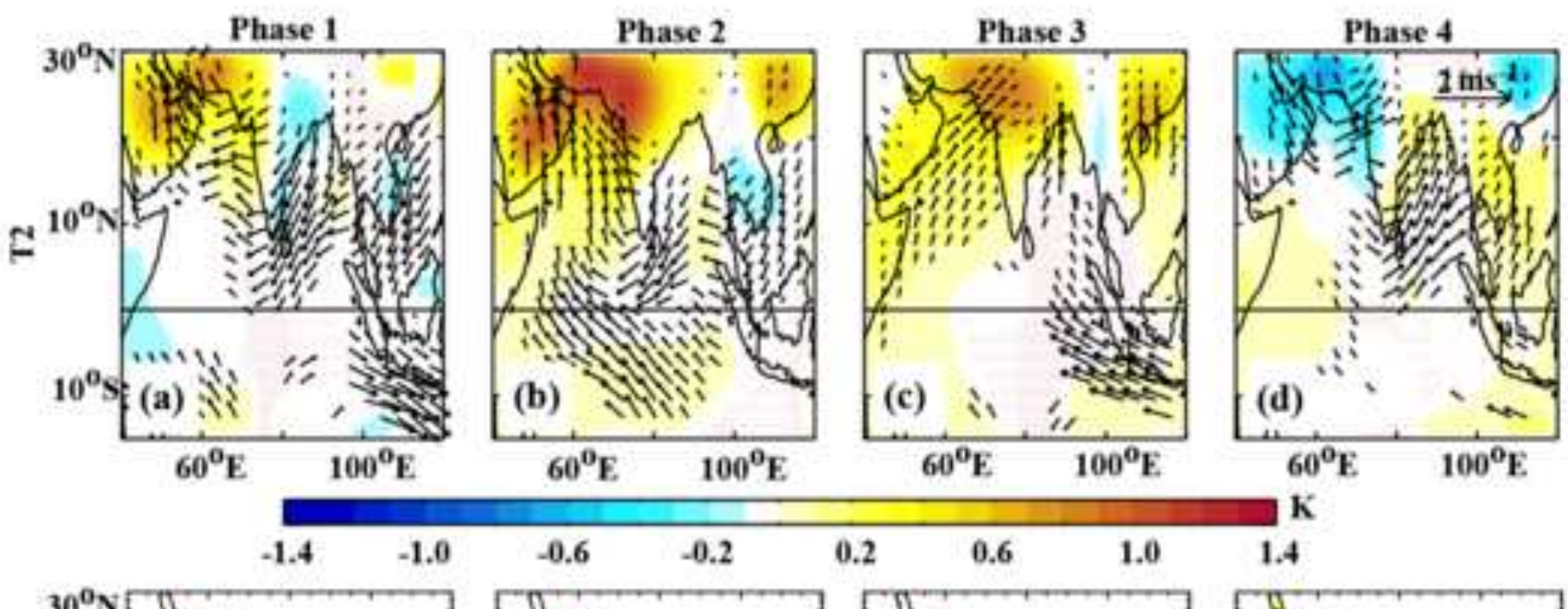

0.2

$0.6 \quad 1.0$
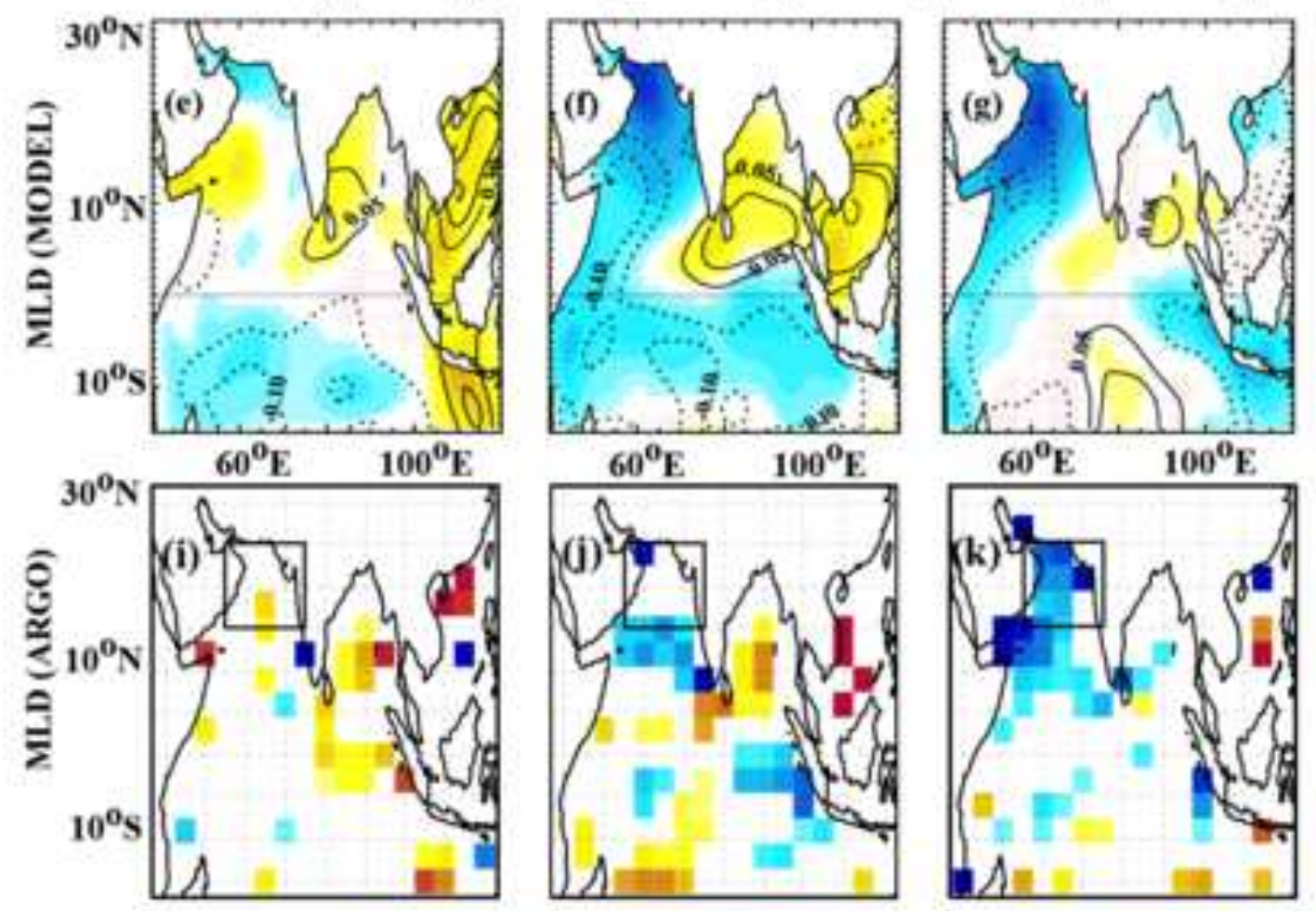

1.4

\section{4}
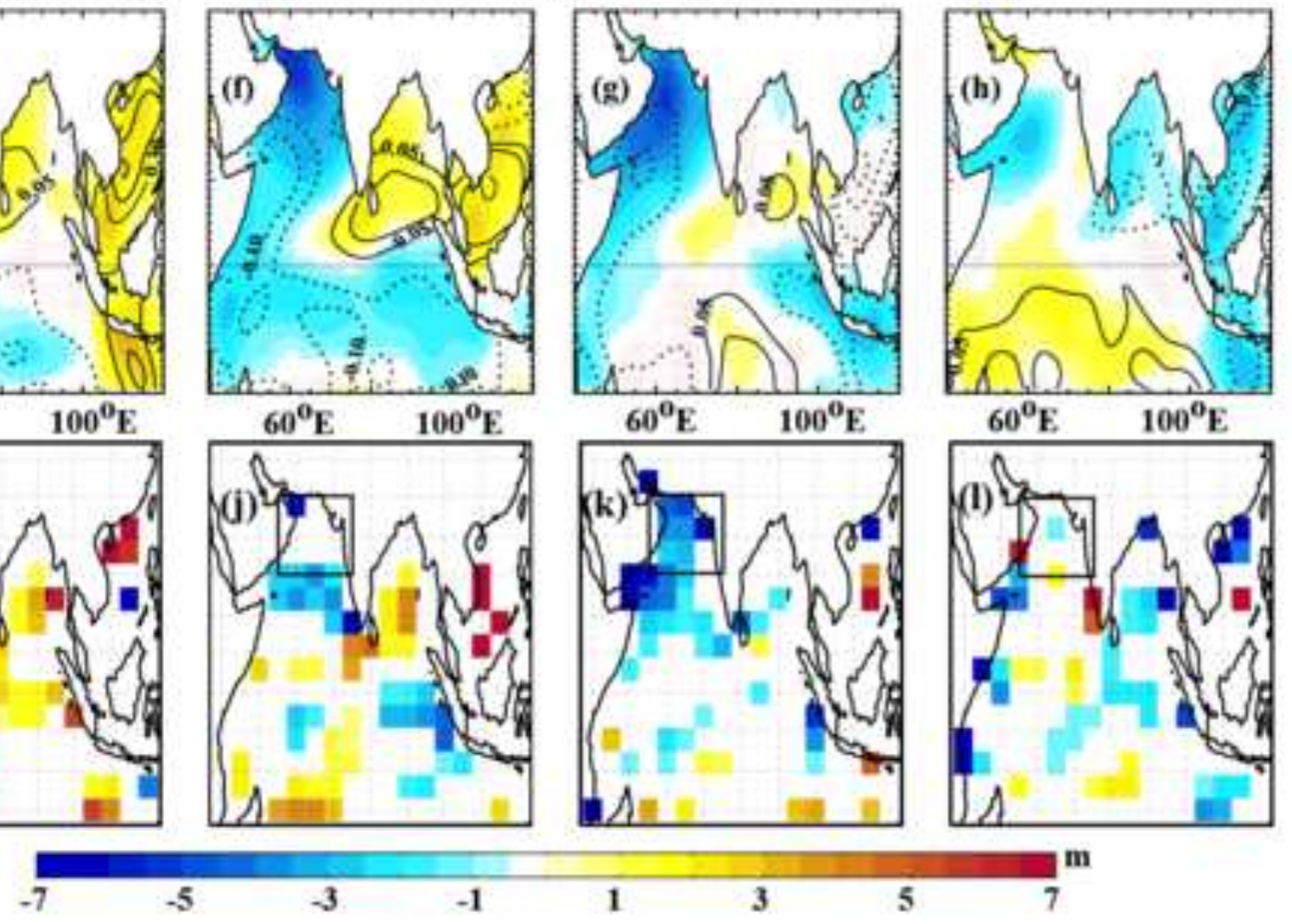


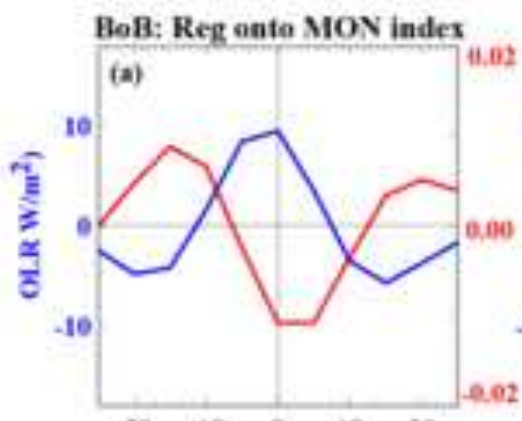

EE1O: Reg onto MON index
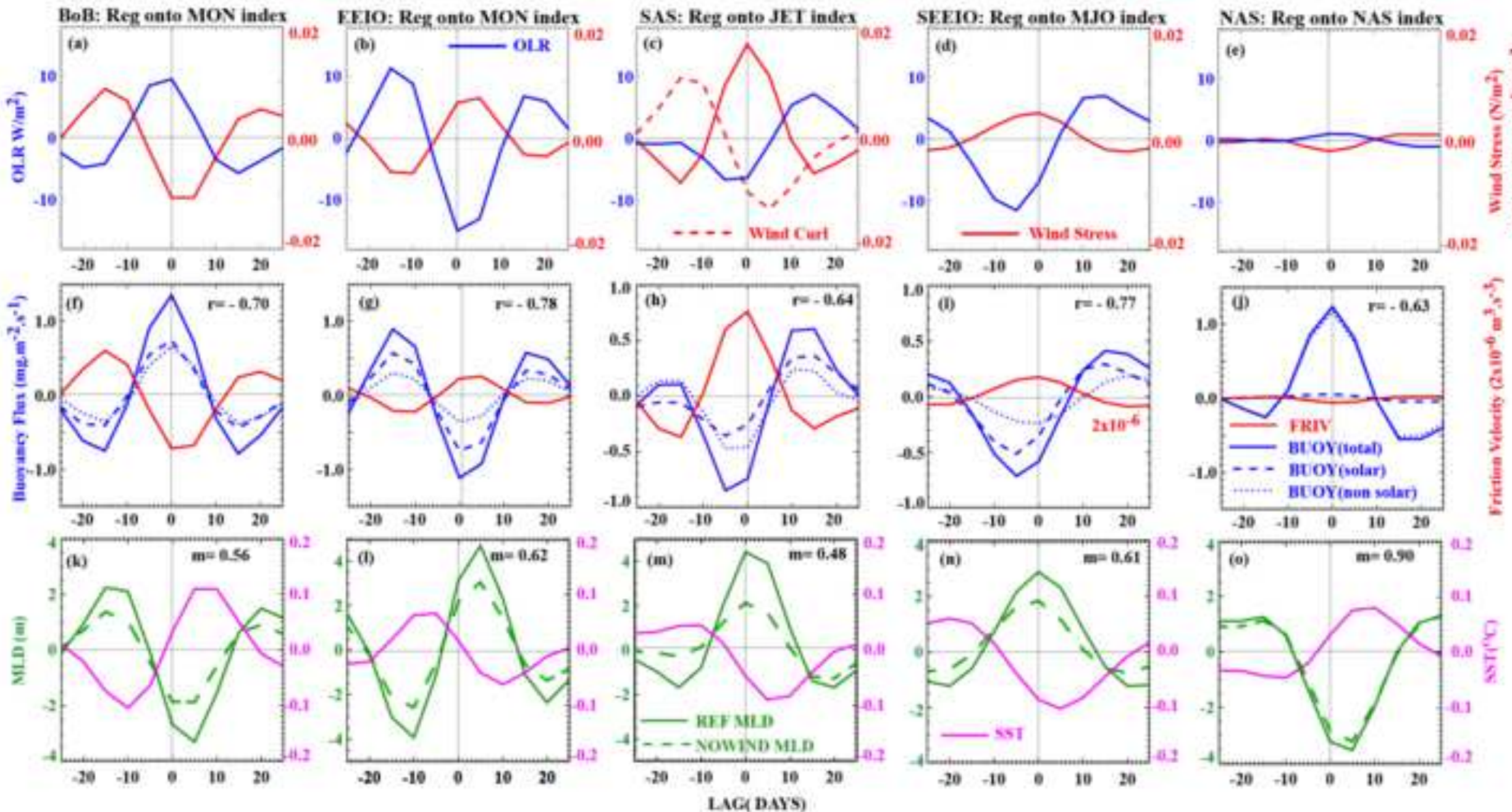
BoB: Reg onto MON index EFIO: Reg onto MON index SAS: Reg onto JET index SEEIO: Reg onto MJO index NAS: Reg onto NAS index
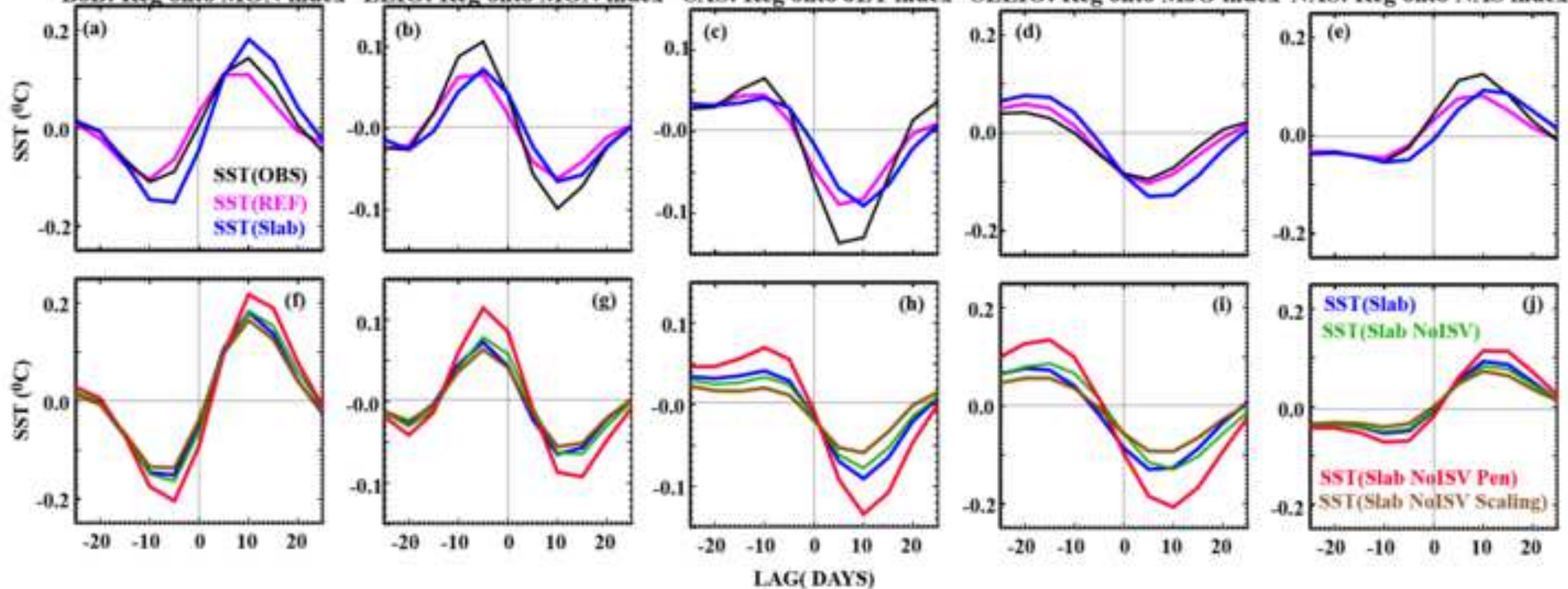


\begin{tabular}{|c|c|c|c|}
\hline Acronym & Name & Season & Boundaries \\
\hline BoB & Bay of Bengal & Summer & {$\left[10^{\circ} \mathrm{N}-20^{\circ} \mathrm{N} ; 80^{\circ} \mathrm{E}-100^{\circ} \mathrm{E}\right]$} \\
\hline EEIO & eastern equatorial Indian Ocean & Summer & {$\left[5^{\circ} \mathrm{S}-5^{\circ} \mathrm{N} ; 70^{\circ} \mathrm{N}-95^{\circ} \mathrm{N}\right]$} \\
\hline SAS & southern Arabian Sea & Summer & {$\left[55^{\circ} \mathrm{E}-75^{\circ} \mathrm{E} ; 2.5^{\circ} \mathrm{N}-12.5^{\circ} \mathrm{N}\right]$} \\
\hline SEEIO & southeastern equatorial Indian Ocean & Winter & {$\left[8^{\circ} \mathrm{S}-2^{\circ} \mathrm{N} ; 85^{\circ} \mathrm{E}-105^{\circ} \mathrm{E}\right]$} \\
\hline NAS & northern Arabian Sea & Winter & {$\left[15^{\circ} \mathrm{N}-25^{\circ} \mathrm{N} ; 55^{\circ} \mathrm{E}-75^{\circ} \mathrm{E}\right]$} \\
\hline
\end{tabular}

